\title{
Aerothermodynamic Design of the Mars Science Laboratory Heatshield
}

\author{
Karl T. Edquist* and Artem A. Dyakonov ${ }^{\dagger}$ \\ NASA Langley Research Center, Hampton, Virginia, 23681 \\ Michael J. Wright $\ddagger$ and Chun Y. Tang ${ }^{\S}$ \\ NASA Ames Research Center, Moffett Field, California, 94035
}

\begin{abstract}
Aerothermodynamic design environments are presented for the Mars Science Laboratory entry capsule heatshield. The design conditions are based on Navier-Stokes flowfield simulations on shallow (maximum total heat load) and steep (maximum heat flux, shear stress, and pressure) entry trajectories from a 2009 launch. Boundary layer transition is expected prior to peak heat flux, a first for Mars entry, and the heatshield environments were defined for a fully-turbulent heat pulse. The effects of distributed surface roughness on turbulent heat flux and shear stress peaks are included using empirical correlations. Additional biases and uncertainties are based on computational model comparisons with experimental data and sensitivity studies. The peak design conditions are $197 \mathrm{~W} / \mathrm{cm}^{2}$ for heat flux, $471 \mathrm{~Pa}$ for shear stress, 0.371 Earth $\mathrm{atm}$ for pressure, and $5477 \mathrm{~J} / \mathrm{cm}^{2}$ for total heat load. Time-varying conditions at fixed heatshield locations were generated for thermal protection system analysis and flight instrumentation development. Finally, the aerothermodynamic effects of delaying launch until 2011 are previewed.
\end{abstract}

\section{Nomenclature}

$\begin{array}{ll}A & \text { reference area, } \frac{1}{4} \pi D^{2}\left(m^{2}\right) \\ C_{D} & \text { drag coefficient, } D / q_{\infty} A \\ D & \text { aeroshell diameter }(\mathrm{m}) \\ D_{i m} & \text { multi-component diffusion coefficient }\left(\mathrm{m}^{2} / \mathrm{s}\right) \\ c_{i} & \text { species mass fraction } \\ H & \text { total enthalpy }(\mathrm{J} / \mathrm{kg}) \\ h_{i} & \text { species enthalpy }(\mathrm{J} / \mathrm{kg}) \\ k & \text { roughness height }(\mathrm{mm}) \\ k^{+} & \text {roughness Reynolds number, } \rho_{w} U_{\tau} k_{s} / \mu_{w} \\ k_{c} & \text { thermal conductivity }(\mathrm{W} / \mathrm{m}-\mathrm{K}) \\ k_{s} & \text { equivalent sand-grain roughness height }(\mathrm{mm}) \\ L / D & \text { lift-to-drag ratio } \\ m & \text { entry system mass }(\mathrm{kg}) \\ p & \text { pressure (Earth atm, } 1 \text { Earth } a t m=101,325 \mathrm{~Pa}) \\ Q & \text { convective total heat load, } \int q d t\left(\mathrm{~J} / \mathrm{cm} \mathrm{m}^{2}\right) \\ q & \text { convective heat flux }\left(\mathrm{W} / \mathrm{cm}^{2}\right) \\ q_{\infty} & \text { freestream dynamic pressure, } \frac{1}{2} \rho_{\infty} V_{\infty}^{2}(P a) \\ R e_{\infty} & \text { freestream Reynolds number, } \rho_{\infty} V_{\infty} D / \mu_{\infty}\end{array}$

*Aerospace Engineer, Atmospheric Flight and Entry Systems Branch, Mail Stop 489, Senior Member, Karl.T.Edquist@nasa.gov.

${ }^{\dagger}$ Aerospace Engineer, Atmospheric Flight and Entry Systems Branch, Mail Stop 489, Member.

${ }^{\ddagger}$ Senior Research Scientist, Reacting Flow Environments Branch, Mail Stop 230-2, Associate Fellow.

${ }_{\S}^{\S}$ Senior Research Scientist, Reacting Flow Environments Branch, Mail Stop 230-2, Member. 


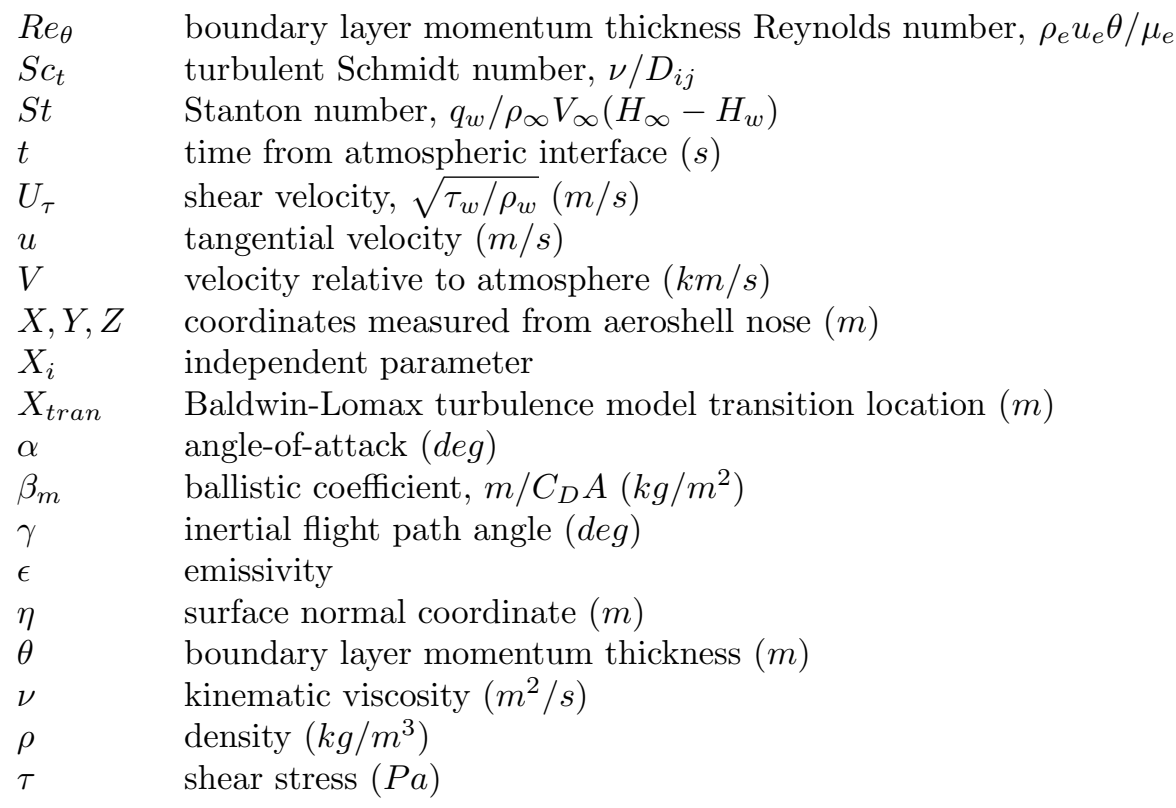

Acronyms

AEDC Arnold Engineering Development Center

AWG Aeroheating Working Group

B-L Baldwin-Lomax

CFD Computational Fluid Dynamics

DPLR Data Parallel Line Relaxation

LAURA Langley Aerothermodynamic Upwind Relaxation Algorithm

MEADS MEDLI Entry Air Data System

MEDLI MSL Entry, Descent, and Landing Instrumentation

MISP MEDLI Integrated Sensor Plugs

MSL Mars Science Laboratory

PICA Phenolic Impregnated Carbon Ablator

RSS Root Sum Square

SLA Super Lightweight Ablator

SST Shear Stress Transport

TPS Thermal Protection System

\section{Subscripts}

$\begin{array}{ll}D & \text { aeroshell diameter } \\ e & \text { boundary layer edge }\left(H_{e}=0.995 H_{\infty}\right) \\ \text { trim } & \text { aerodynamic trim condition } \\ w & \text { surface condition } \\ w, 0 & \text { smooth surface condition } \\ w, k & \text { rough surface condition } \\ \infty & \text { freestream condition }\end{array}$

\section{Introduction}

NaSA's Mars Science Laboratory (MSL) entry system ${ }^{1}$ will deliver a large rover $(>900 \mathrm{~kg})$ to the surface of Mars within a distance of $10 \mathrm{~km}$ from the landing target. The entry system will land the rover using an aeroshell and parachute architecture that has successfully delivered payloads on Mars starting with the Viking ${ }^{2}$ landers and continuing with Pathfinder, ${ }^{3}$ the Mars Exploration Rovers, ${ }^{4}$ and Phoenix. ${ }^{5}$ Prior to 
supersonic parachute deployment, the MSL entry capsule will fly with a hypersonic lift-to-drag ratio $(L / D)$ of 0.24 at a trim angle-of-attack $\left(\alpha_{\text {trim }}\right)$ of $16 \mathrm{deg}$ using active guidance and thrusters to control lift vector direction. Ballast mass will be used to give the capsule the necessary radial center-of-gravity offset for the desired $\alpha_{\text {trim }}$ and $L / D$. MSL launch, until recently scheduled for the Fall of 2009, has been delayed until late 2011 with landing in Summer of 2012.

The interaction between the MSL aeroshell and Martian atmosphere will dissipate more than 99\% of the entry system's initial kinetic energy, mostly in the form of heat. MSL's heatshield thermal protection system $^{6-8}$ (TPS) will keep the aeroshell interior from these extreme environments. TPS material response is primarily a function of convective heat flux via conduction and diffusion (radiation is negligible for MSL):

$$
q_{w}=\left(k_{c} \frac{\partial T}{\partial \eta}+\rho \sum D_{i m} h_{i} \frac{\partial c_{i}}{\partial \eta}\right)_{w}
$$

The objective of this paper is to summarize the MSL aerothermodynamic design process and conditions (heat flux, shear stress, pressure, and total heat load) in support of heatshield TPS analysis ${ }^{6}$ and testing, ${ }^{7}$ as well as development of engineering instrumentation. ${ }^{9}$ A companion paper ${ }^{10}$ covers design environments for the entry capsule backshell and parachute cover. MSL's large aeroshell and high ballistic coefficient $\left(\beta_{m}\right)$ will result in boundary layer turbulent transition prior to peak heating (a first for Mars entry), leading to more severe aerothermodynamic conditions than any previous Mars entry heatshield. Consequently, significant effort has been spent to quantify the aerothermodynamic environments with ground testing and analytical predictions. Computational ${ }^{11-15}$ and experimental ${ }^{16-21}$ aerothermodynamics analyses have been performed for various MSL aeroshell configurations and design trajectories. This paper covers the aerothermodynamic analysis used to develop the flight heatshield TPS for the original 2009 launch opportunity.

\section{A. Aeroshell and Heatshield Thermal Protection System}

The MSL aeroshell is a 4.5-meter diameter spherically-blunted 70-degree half-angle cone forebody with a triconic afterbody (Figure 1a). All previous major NASA Mars capsules used the same forebody shape and Lockheed Martin's Super Lightweight Ablator ${ }^{22}$ (SLA-561V) TPS material on the heatshield. The unprecedented magnitude of the MSL environments led to SLA-561V test anomalies ${ }^{7}$ and necessitated switching to the Phenolic Impregnated Carbon Ablator ${ }^{23}$ (PICA). PICA is developed by Fiber Materials Incorporated (FMI) and was first used on the Stardust Earth return capsule, ${ }^{24}$ but has never been used on a Mars heatshield nor in a tiled configuration (Figure 1b). PICA was also under consideration for the Orion Crew Exploration Vehicle lunar return capsule. A uniform PICA thickness of 1.25 in was established for MSL after the material switch and prior to completion of the aerothermodynamic design environments and TPS analysis. Therefore, the thickness was determined by the entry system mass constraints rather than through thermal analysis in response to a particular heat pulse. ${ }^{6}$ Instead of deriving a minimum required thickness, the TPS analysis focused on ensuring that 1.25 in is sufficient to withstand the heat pulse with sufficient margin and acceptable risk. The PICA sizing models predict significant recession (more than half of the initial thickness) in response to the severe environments, another first for a Mars heatshield.

Numerous tests 8 were conducted to develop PICA for MSL's purposes and TPS analyses have since confirmed that $1.25 \mathrm{in}$ is sufficient to meet the thermal requirements with acceptable risk. ${ }^{6}$ PICA application has been completed for the flight heatshield in anticipation of the original 2009 launch date. PICA was installed on the heatshield in tile form (Figure 1b) due to manufacturing size constraints. Requirements were placed on the gap/flow angles and maximum gap length to minimize adverse effects due to the boundary layer. A total of 113 tiles (27 unique shapes) was used to cover the heatshield. Adhesive materials were used to attach the tiles to the aeroshell structure and to fill the gaps between tiles. The bondline interface must stay below temperature limits $\left(225\right.$ to $250^{\circ} \mathrm{C}$ ) to maintain bond integrity and aeroshell structure performance. ${ }^{6}$ The effects of protruding gap fillers were analyzed computationally, ${ }^{25}$ but were not explicitly included in the design environments because of low probability at high heat fluxes and for gaps perpendicular to the oncoming flow ${ }^{7}$ where bump factors could pose a risk to the TPS. 


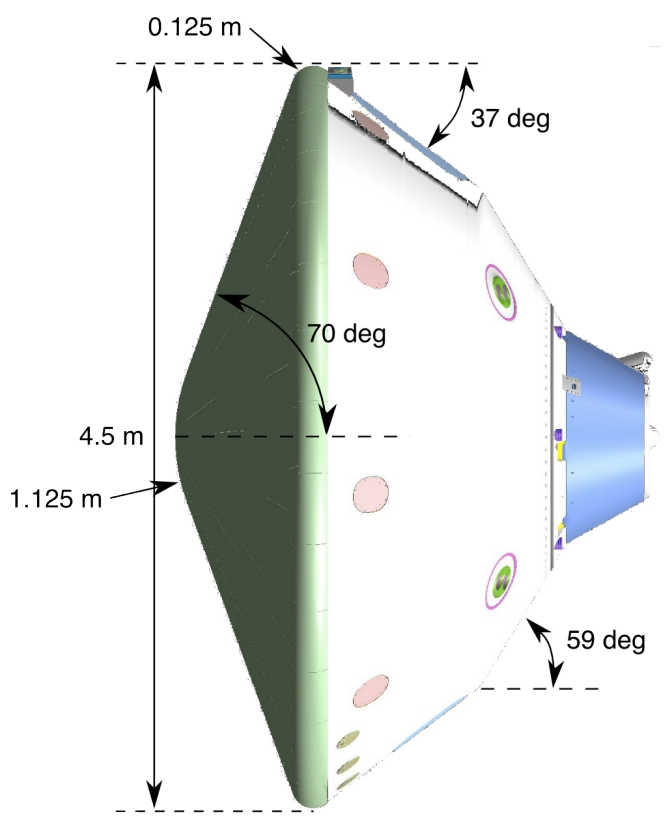

(a) Geometry

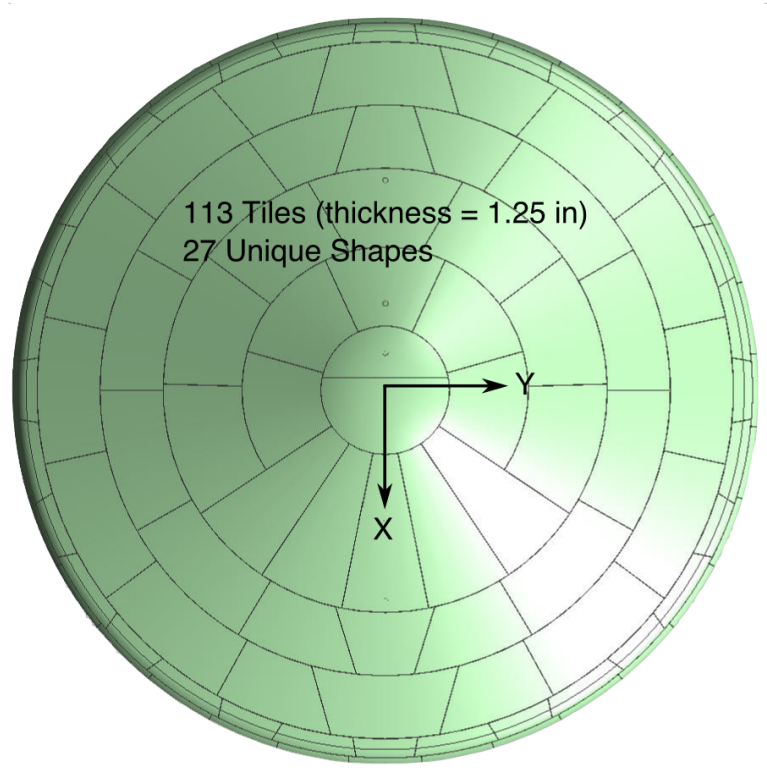

(b) PICA Heatshield TPS Tiles

Figure 1. MSL Aeroshell

\section{B. Aerothermodynamic Design Trajectories}

Two entry trajectories (08-TPS-01a and 08-TPS02) were used to define MSL's heatshield aerothermodynamic conditions (Figure 2 and Table 1). The trajectories were designed with a high entry velocity to give upper bound aerothermal loads. The trajectories differ only in entry flight path angle $(\gamma)$. The shallow 08TPS-01a trajectory (entry $\gamma=-14$ deg) has a longer time of flight and the highest integrated total heat load, which typically requires the largest TPS thickness. The steep 08TPS-02 trajectory (entry $\gamma=-15.5 \mathrm{deg}$ ) gives the peak instantaneous conditions (heat flux, shear stress, and pressure) for ground test design. The capsule will generate enough lift to achieve nearly horizontal flight leading up to parachute deployment (between 1 and 2 $\mathrm{km} / \mathrm{s})$.

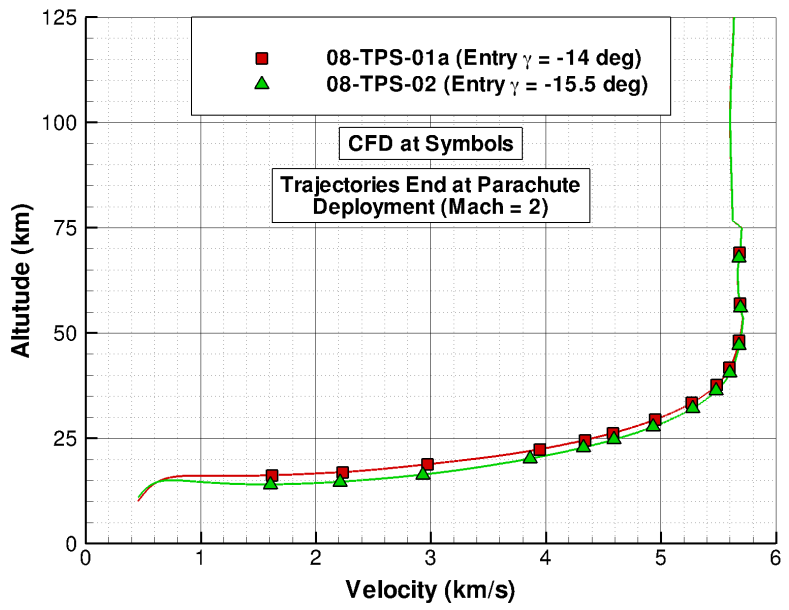

Figure 2. Aerothermodynamic Design Trajectories for the 2009 Launch Opportunity

Table 1. Aerothermodynamic Design Trajectories for the 2009 Launch Opportunity

\begin{tabular}{r|c} 
& 08-TPS-01a / 08-TPS-02 \\
\hline \hline Launch Date & $09 / 20 / 09$ \\
Arrival Date & $07 / 20 / 10$ \\
Entry Mass $(\mathrm{kg})$ & 3380 \\
Entry $V_{\infty}(\mathrm{km} / \mathrm{s})$ & 5.63 \\
Entry $\gamma(\mathrm{deg})$ & $-14 /-15.5$ \\
Time at Parachute Deployment $(\mathrm{s})$ & $280 / 249$
\end{tabular}




\section{MSL Compared to Previous Missions}

Figure 3 and Table 2 compare MSL to past successful Mars missions, all of which used SLA-561V in less severe heatshield conditions than MSL will experience. The unprecedented MSL entry system size and mass will lead to a much more aggressive atmospheric entry than has been previously attempted. The MSL rover mass alone $(850 \mathrm{~kg}$ for the design trajectories, $>900 \mathrm{~kg}$ for the flight hardware) is similar to the total entry system masses for the Mars Exploration Rovers (MER). MSL's landing mass includes the Sky Crane $^{1}$ descent stage since it will reach the ground after releasing the rover. MSL's high ballistic coefficient leads to higher aerothermal and structural loads since velocity is maintained deeper into the atmosphere. Furthermore, MSL's large heatshield surface area enhances the likelihood of turbulent transition with longer boundary layer running lengths. Finally, MSL will fly at a higher angle-of-attack than has ever been attempted to achieve the desired $L / D$; this further exacerbates the aerothermal loads by allowing longer running lengths for turbulent boundary layer development. MSL's turbulent heating levels led to SLA-561V test failures ${ }^{7}$ and the thickest Mars heatshield ever built.

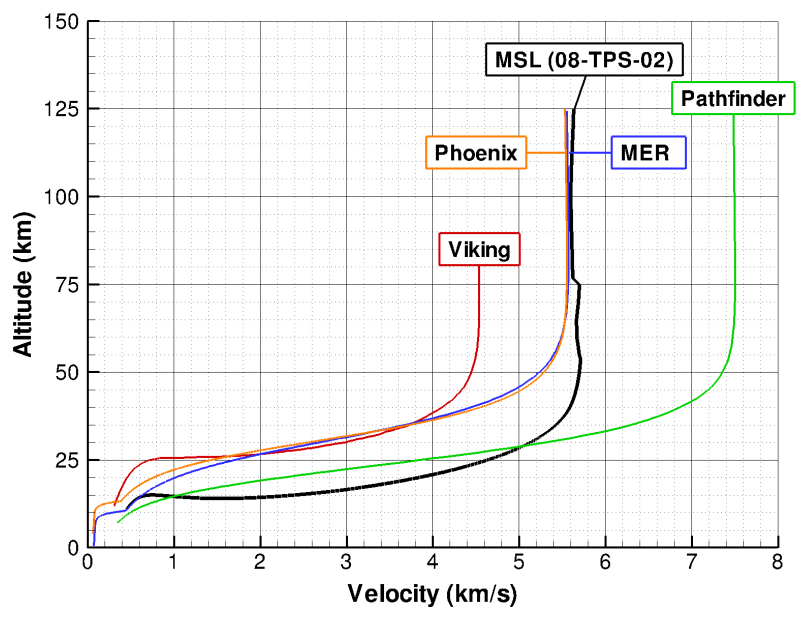

Figure 3. Mars Entry Trajectory Comparison

Table 2. Mars Aeroshell and Entry Trajectory Comparison

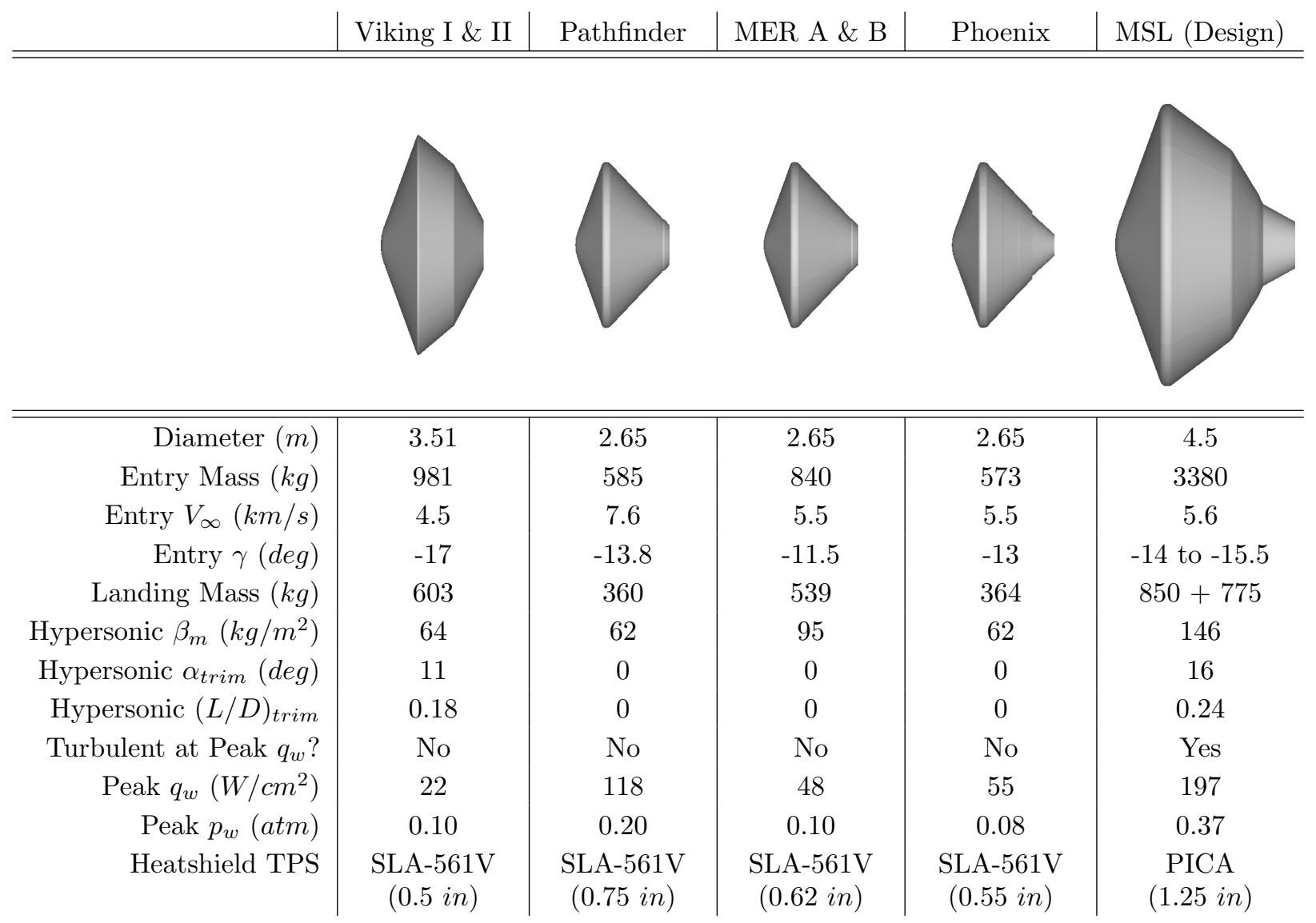




\section{Computational Models}

There exists no ground-based facility that can reproduce the high-temperature non-equilibrium $\mathrm{CO}_{2}-\mathrm{N}_{2}$ thermodynamic conditions that exist at Mars hypersonic flight conditions. Consequently, extensive use of Navier-Stokes computational fluid dynamics (CFD) was required to define the MSL aerothermodynamics. Many challenges ${ }^{26}$ exist when calculating the aerothermodynamic environments for a hypersonic Mars entry capsule. The high temperatures generated behind the bow shock leads to chemical and thermal nonequilibrium conditions that require models whose validity at Mars flight conditions often cannot be verified. For MSL, verification and validation of the CFD models was accomplished through code-to-code comparisons and anchoring to perfect-gas and high-enthalpy test data. ${ }^{16-21}$

The MSL aerothermodynamic environments are based on the Langley Aerothermodynamic Upwind Relaxation Algorithm ${ }^{27}$ (LAURA) and Data Parallel Line Relaxation ${ }^{28}$ (DPLR) Navier-Stokes codes. Both codes have been used for previous Mars and Earth entry capsule flowfield predictions, including Pathfinder, ${ }^{29}$ Phoenix,${ }^{30}$ and Genesis Sample Return Capsule. ${ }^{31,32}$ LAURA is also being used ${ }^{33}$ to predict MSL's aerodynamic characteristics in the hypersonic and supersonic continuum flow regimes, including RCS interference effects. ${ }^{34}$ For MSL, turbulent solutions using the Baldwin-Lomax algebraic model ${ }^{35}$ were obtained for the heatshield based on the expectation of turbulent transition in flight. It will be shown that the Baldwin-Lomax model agrees well with fully-turbulent test data. DPLR solutions were used for verification and validation of the LAURA results and sensitivity analyses using the Shear Stress Transport ${ }^{36}$ (SST) turbulence model. The model assumptions for flight calculations were as follows:

- Turbulent boundary layer: Baldwin-Lomax algebraic model, transition forced at stagnation point

- Chemical non-equilibrium $\left(\mathrm{CO}_{2}, \mathrm{CO}, \mathrm{N}_{2}, \mathrm{O}_{2}, \mathrm{NO}, \mathrm{C}, \mathrm{N}, \mathrm{O}, 0.97\right.$ and 0.03 freestream mass fractions for $\mathrm{CO}_{2}$ and $\mathrm{N}_{2}$, respectively)

- Thermal non-equilibrium (translational and vibrational temperatures)

- Radiative-equilibrium wall: $q_{w}=\epsilon \sigma T_{w}^{4}, \epsilon=0.89, \sigma=5.67 \times 10^{-8} \mathrm{~W} /\left(\mathrm{m}^{2}-K^{4}\right)$

- Super-catalytic wall: recombination of $\mathrm{CO}_{2}$ and $\mathrm{N}_{2}$ to freestream mass fractions

- Non-blowing, smooth wall (distributed roughness effects added post-CFD)

\section{Results}

The following sections summarize the results of applying the process in Figure 4 to define MSL aerothermodynamic design environments. Given freestream conditions along the design trajectories, CFD solutions were obtained using the model assumptions stated previously. Margins were then added to account for CFD model corrections and uncertainties. The end results are the design environments for multiple heatshield locations for the 08-TPS-01a (maximum total heat load) and 08-TPS-02 (maximum heat flux, shear stress, and pressure) entry trajectories. Any changes that affect the entry trajectory, such as entry mass or velocity, required a repeat of the design cycle. Due to the timing of the switch to PICA, the TPS sizing analysis turned into a exercise to verify that the as-built thickness $(1.25 \mathrm{in})$ was sufficient rather than to determine a minimum required thickness for a particular heat pulse. ${ }^{6}$

MSL aeroshell and heatshield TPS development was a joint effort between NASA Langley and Ames Research Centers (aerothermodynamic analysis, TPS modeling and testing), NASA Jet Propulsion Laboratory (JPL, project management, verification and validation), Lockheed Martin Astronautics (aeroshell development), and FMI (PICA manufacturer). The aerothermodynamic analyses that supported the PICA design was overseen by the MSL Aeroheating Working Group (AWG) consisting of members from NASA, JPL, and Lockheed Martin. The AWG served as the venue for discussing the state of the aerothermal design environments, interpreting test results, and proposing additional testing and analysis. The aerothermal design process and results were reviewed by project management and subject matter experts, both in detailed and system-level project reviews. The data to follow reflect the final analysis vetted through the AWG and used to size and test the flight heatshield TPS for the original 2009 launch opportunity. A preview is also given of environments for the new launch date in 2011. 


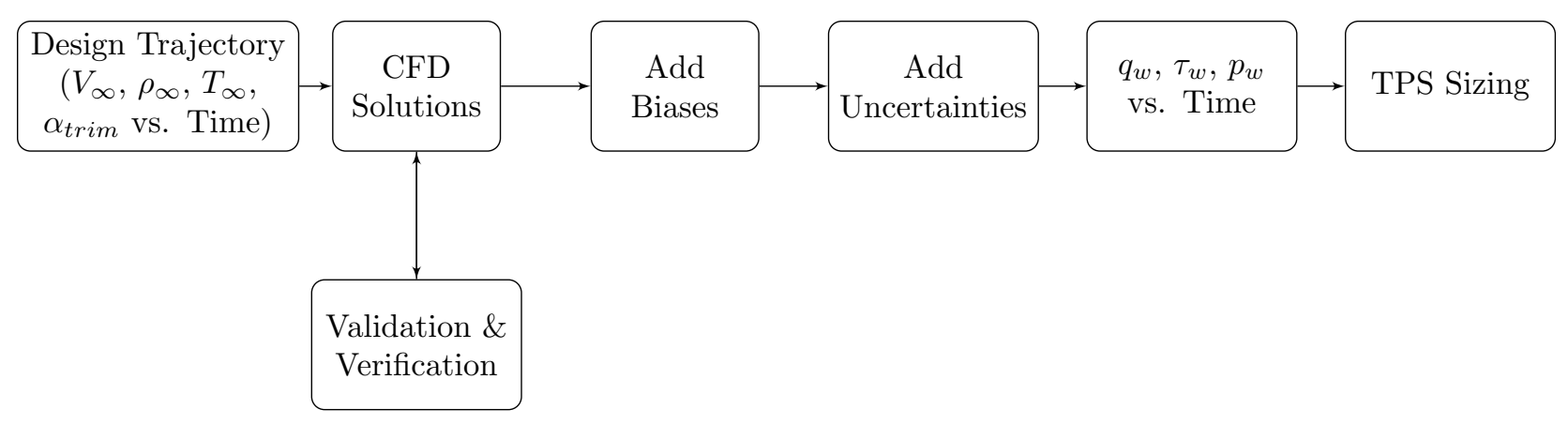

Figure 4. Aerothermodynamic Design Process

\section{A. Boundary Layer Transition}

MSL's large aeroshell, high ballistic coefficient, and non-zero trim angle-of-attack is expected to lead to forebody boundary layer transition prior to peak heating. This assessment was made using a simplified method based on exceeding a critical laminar boundary layer momentum thickness Reynolds number:

$$
\operatorname{Re}_{\theta}=\frac{\rho_{e} u_{e} \theta}{\mu_{e}}
$$

where the boundary layer momentum thickness is defined as:

$$
\theta=\int_{0}^{e} \frac{\rho u}{\rho_{e} u_{e}}\left(1-\frac{u}{u_{e}}\right) d \eta
$$

Boundary layer edge conditions are defined where the total enthalpy is $99.5 \%$ of the freestream value.

A conservative transition criterion of $\operatorname{Re}_{\theta}>200$ was established for the heatshield design environments. Experimental MSL data in perfect gas and high-enthalpy facilities support the use of this transition criterion. ${ }^{20}$ It is acknowledged that using ground-based results to support transition prediction at flight conditions may be inappropriate. However, conservatism was warranted given the uncertainty in predicting transition onset and its significant effect on both heat flux and shear stress for a flagship NASA mission. Figure 5 shows that the LAURA $R e_{\theta}$ on the heatshield leeside $(X<0)$ exceeds 200 prior to the time of peak heat flux on the shallow design trajectory. The highest values of $R e_{\theta}$ are found in the leeside shoulder region where the boundary layer running length is longest. This will be shown to also correspond the area of highest turbulent heat flux and shear stress. In order to conservatively account for turbulence effects on total heat load, both design trajectory heat pulses were assumed to be entirely turbulent. CFD solutions on each trajectory were run using the Baldwin-Lomax algebraic model with transition forced at the stagnation point.

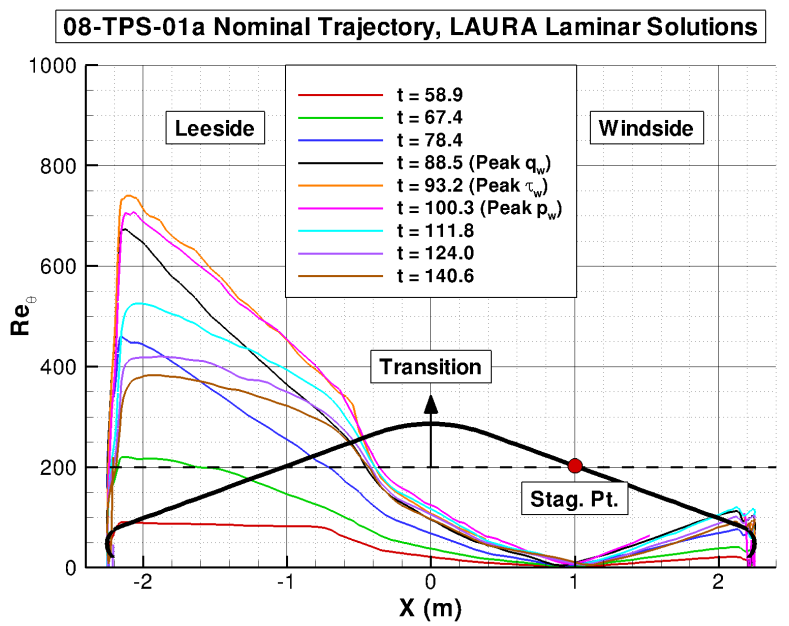

Figure 5. LAURA Laminar Momentum-Thickness Reynolds Number Distributions on the 08-TPS-01a Trajectory 


\section{B. CFD Compared to Experimental Data}

Turbulent transition prior to peak heating is believed to be a first for a Mars entry. Consequently, there exist no flight data to validate CFD turbulence models at Mars conditions. For MSL, turbulence model validation was achieved through comparison to test data. Several MSL experimental tests ${ }^{16-21}$ have been conducted to understand boundary layer transition and the validity of the Baldwin-Lomax model. One of those test programs ${ }^{16}$ was conducted in the Arnold Engineering Development Center (AEDC) Tunnel 9 using perfect gas nitrogen. The facility's wide Reynolds number range allowed data collection at laminar, transitional, and fully-turbulent (untripped) conditions. Laminar and transitional data were collected at Mach 10 conditions. Laminar through fully-turbulent data were obtained at Mach 8 conditions. Perfect gas heating data are valuable for code validation because the heating is a result of conduction only and does not include any diffusion effects (Equation 1). The AEDC test provided an excellent opportunity for CFD code comparison to laminar through turbulent data in a single facility.

LAURA and DPLR solutions were obtained for low (laminar) and high (turbulent) Reynolds numbers at AEDC facility conditions. The codes were run with perfect gas nitrogen and a fixed wall temperature. As with flight predictions, the Baldwin-Lomax solutions were run with transition specified at the stagnation point. The LAURA and DPLR laminar heating compares very well to data at a low Reynolds number (Figure 6a). Both codes are within $10 \%$ of the time-averaged heat transfer at every measurement location. The error bars on the data $(+/-10 \%)$ are shown for reference purposes and do not necessarily represent the actual experimental uncertainty. LAURA and DPLR Baldwin-Lomax turbulent heating at a higher Reynolds number match the data almost as well as the laminar case, especially on the leeside (Figure 6b). The DPLR SST model predicts slightly higher leeside flank heating than both Baldwin-Lomax predictions, as well as the data. The code-to-code differences using the Baldwin-Lomax model are considered to be within normal CFD uncertainties. The small differences between the DPLR Baldwin-Lomax and SST models are also considered insignificant. It should not be surprising that the Baldwin-Lomax algebraic model predicts blunt body turbulent heating as well as the two-equation SST model, given that the flowfield is completely attached and does not require advanced turbulence modeling. Overall, the good comparisons between the CFD codes and AEDC data gave confidence in using the Baldwin-Lomax model for MSL turbulent heating.

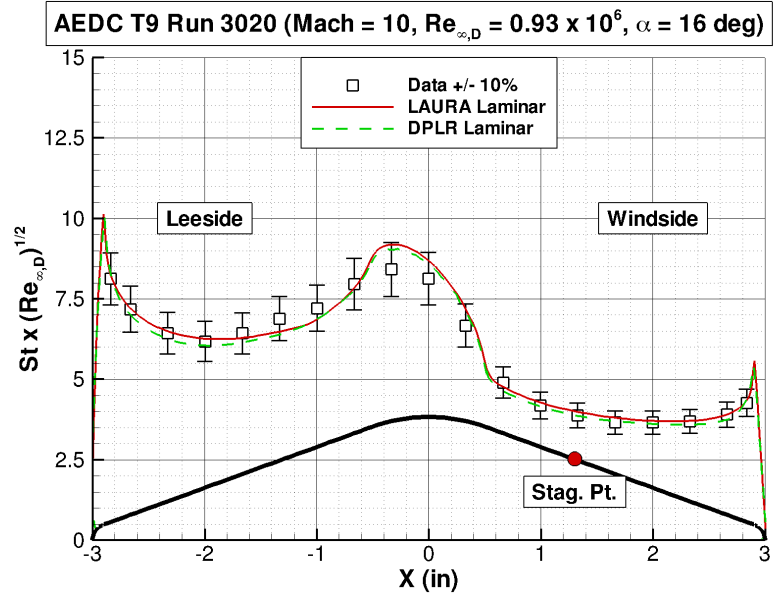

(a) Laminar $\left(\right.$ Mach $\left.=10, \operatorname{Re}_{\infty, D}=0.93 \times 10^{6}, \alpha=16\right)$

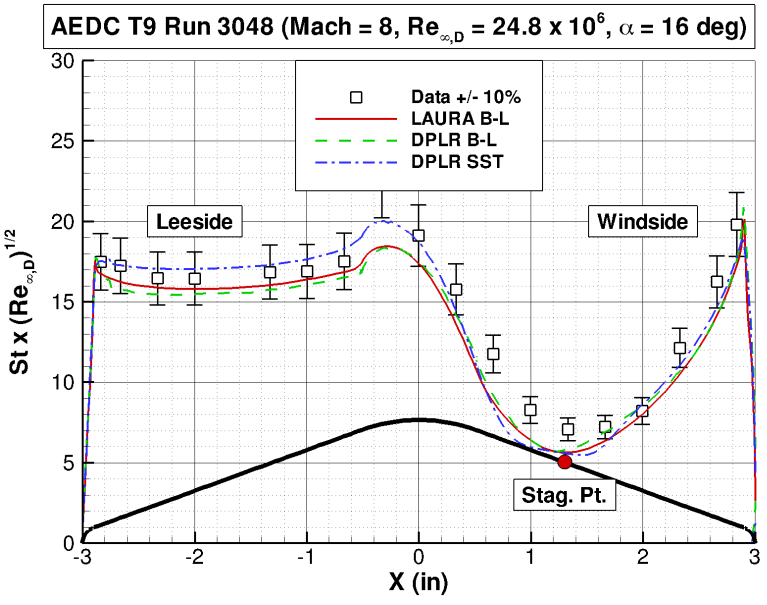

(b) Turbulent $\left(\right.$ Mach $\left.=8, \operatorname{Re}_{\infty, D}=24.8 \times 10^{6}, \alpha=16\right)$

Figure 6. CFD Compared to AEDC Tunnel 9 Data

A heating augmentation was present in the stagnation data from both AEDC and the NASA Langley Research Center's 20-Inch Mach 6 Air Tunnel. ${ }^{20}$ For example, Figure 6b shows computed stagnation heating more than $10 \%$ below the data. The origin of the heating discrepancy is unknown, but it may be related to turbulence or unsteady acoustic feedback from the boundary layer edge. The discrepancy between computed and measured stagnation heating in Figure $6 \mathrm{~b}$ may indicate the beginnings of that phenomenon. The heating bump exhibited in Figure $6 \mathrm{~b}$ and other data has been included in the MSL design environments as an uncertainty near the stagnation point. 


\section{CFD Code Comparison at Flight Conditions}

No Mars flight data exist that can be used to validate turbulent heating predictions at flight conditions. Pathfinder thermocouple data ${ }^{37}$ indicate laminar conditions or possibly early onset of transition at the shoulder, but no definite signs of turbulence. Given the lack of Mars flight data, CFD code comparisons were the next best option to verify the Baldwin-Lomax model implementations at MSL flight calculations. The entry trajectory (07-25) that was used for this exercise is analogous to 08-TPS-02, but with a $5.8 \mathrm{~km} / \mathrm{s}$ entry velocity instead of 5.9. Figure 7 shows a comparison of baseline LAURA and DPLR Baldwin-Lomax environments at times of peak heat flux, peak shear stress, and peak pressure on the 07-25 trajectory. At the leeside shoulder, the heat flux (Figure 7a) and total heat load (Figure 7d) results are nearly identical between codes. The discrepancies at other locations are considered to be within normal CFD modeling uncertainties. The shear stress agreement is similar to heat flux (Figure $7 \mathrm{~b}$ ) and the pressures match very well (Figure 7c). Based on the good agreement between LAURA and DPLR, no uncertainties were added to account for code-to-code Baldwin-Lomax model variability in the flight design environments.

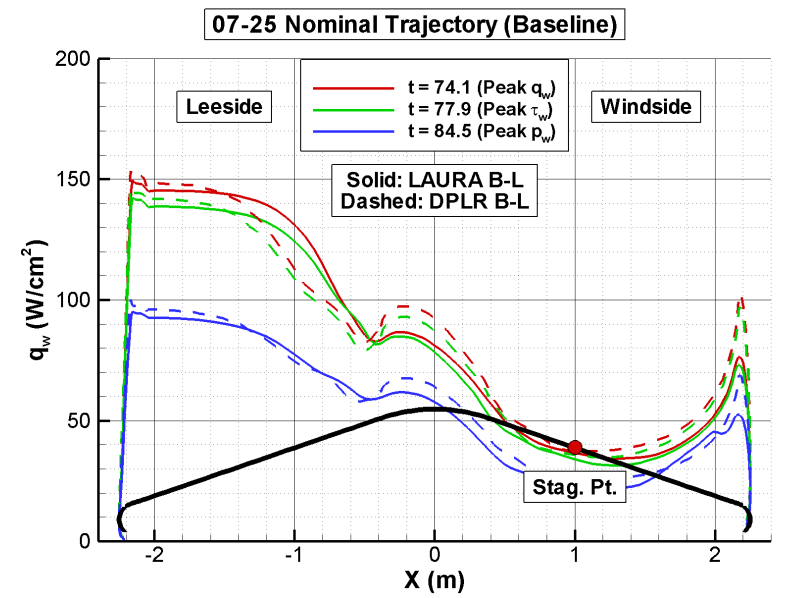

(a) Heat Flux

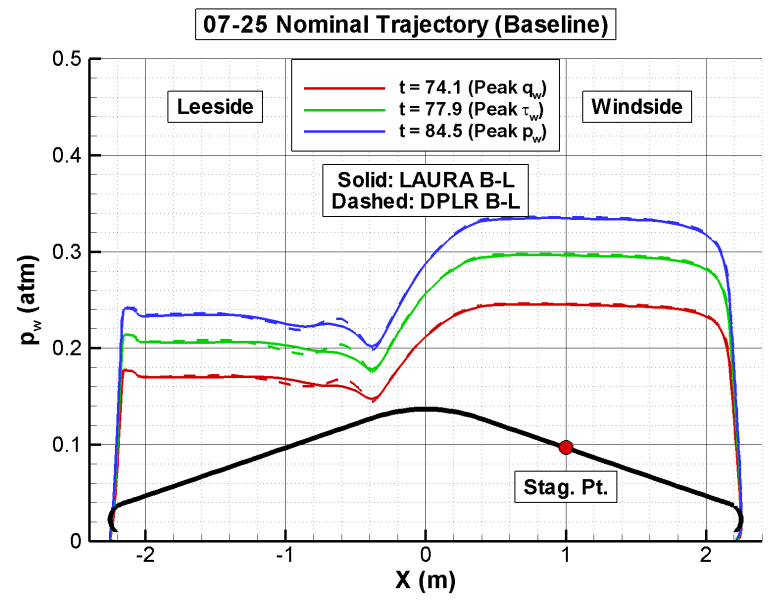

(c) Pressure

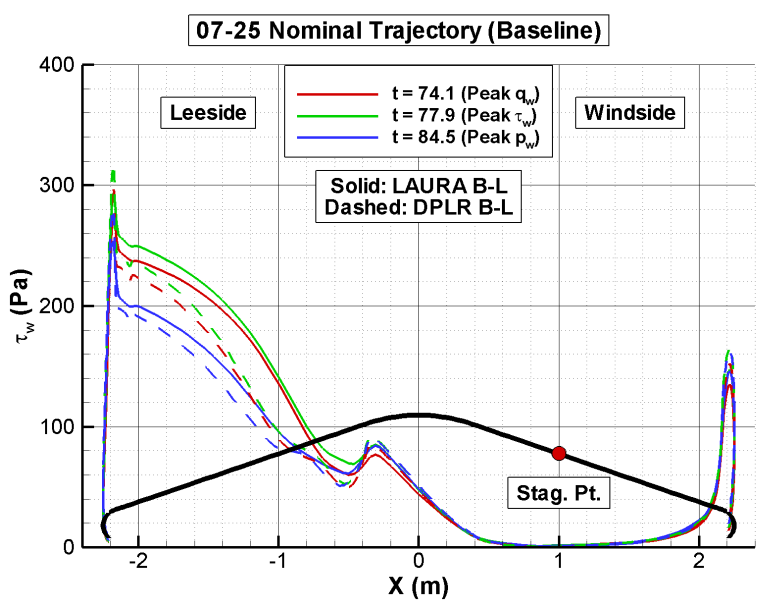

(b) Shear Stress

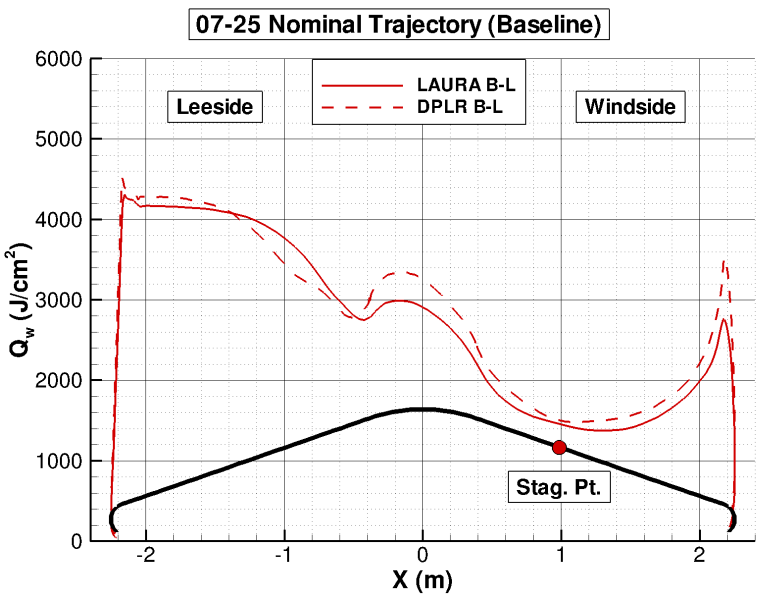

(d) Total Heat Load

Figure 7. LAURA and DPLR Baldwin-Lomax Solutions on the 07-25 Trajectory (No Uncertainties) 


\section{Aerothermodynamic Partials}

There are dozens of models in LAURA and DPLR needed to simulate the chemically and thermally nonequilibrium flowfield that is predicted to surround the MSL heatshield at flight conditions. These models are governed by numerous parameters and often have questionable applicability for Mars hypersonic conditions. Some phenomena that affect aerothermodynamics simply may be beyond state-of-the-art CFD capabilities. The expectation of turbulent conditions during flight adds yet another source of modeling uncertainty that pushes the limits of existing CFD models. In light of the numerous models that affect CFD predictions, an attempt was made to quantify some of their uncertainties and effects on the MSL aerothermodynamic design conditions. Previous attempts ${ }^{38}$ have been made to quantify CFD uncertainty effects on Pathfinder heating calculations. The MSL project had neither the time nor the resources to perform a rigorous uncertainty analysis. Rather, a limited set of models and phenomena that were deemed important were considered. For the most part, conservative assumptions (e. g. a fully-turbulent heat pulse) were chosen up front to avoid having to estimate more detailed CFD uncertainty effects on the MSL heatshield design conditions.

The MSL design heatshield environments were specified to be the baseline LAURA results using the stated model assumptions plus partials (biases and uncertainties) obtained through code validation and sensitivity analyses:

$$
(q, \tau, p)_{\text {Design }}=(q, \tau, p)_{L A U R A}+\Delta(q, \tau, p)_{\text {Bias }}+\Delta(q, \tau, p)_{U n c e r t}
$$

Biases are corrections to the heat flux, shear stress, and pressure due to CFD model deficiency or inaccuracy; they are applied sequentially to the baseline environments:

$$
\Delta(q, \tau, p)_{B i a s}=\sum \frac{\partial(q, \tau, p)_{w}}{\partial X_{i}}
$$

where $X_{i}$ represents those parameters that are expected to alter the environments. Uncertainties are those phenomena that may change the environments; they are treated as random independent occurrences and are combined using a Root Sum Square (RSS) approach:

$$
\Delta(q, \tau, p)_{\text {Uncert }}=\sqrt{\sum\left(\frac{\partial(q, \tau, p)_{w}}{\partial X_{i}}\right)^{2}}
$$

Table 3 summarizes the partials and applicable parameter ranges. The Surface Catalysis bias reflects the use of the super-catalytic boundary condition, which forces the recombination of $\mathrm{CO}_{2}$ and $\mathrm{N}_{2}$ to their freestream mass fractions. In the absence of reliable data, the super-catalytic assumption is frequently used ${ }^{26}$ because it gives the highest surface chemistry contribution to heat flux (Equation 1), and thus is conservative for TPS design. Figure 8 illustrates the conduction and diffusion contributions to super-catalytic heat flux on the 08-TPS-02 trajectory. At the time of peak heating, diffusion is predicted to contribute about two-thirds of the total heat flux at the leeside shoulder. The individual contributions are about equal near the stagnation point. Pathfinder thermocouple data suggests that, for those flight environments, the heating was $85-100 \%$ of super-catalytic CFD computations. ${ }^{37}$ The Turbulent Augmentation bias (5\%) reflects the small differences between CFD and AEDC turbulent data on the leeside flank (Figure 6b). The Distributed Roughness bias is discussed below.

LAURA solutions were used to determine most of the uncertainties by individually varying the independent parameter and calculating the effect on the environments. Parameter ranges were taken from either separate analyses (e. g. Trim Angle-of-Attack and Shape Change) or expert judgment (e. g. Turbulent Schmidt Number). Differences between the nominal and dispersed environments (heat flux, shear stress, and pressure) were used as the uncertainties at a given heatshield location. All CFD-based uncertainties were calculated at the time of peak heat flux and summed using the RSS method (Equation 6) before being 
Table 3. Aerothermodynamic Partials

\begin{tabular}{c|c|c|c|c} 
Type & Independent Parameter & Baseline & Minimum & Maximum \\
\hline \hline \multirow{5}{*}{ Bias } & Surface Catalysis & Super-Catalytic & N/A & N/A \\
& Distributed Roughness & Eqns. $7,9\left(k_{s}=0.6 \mathrm{~mm}\right)$ & $\mathrm{N} / \mathrm{A}$ & $\mathrm{N} / \mathrm{A}$ \\
& Turbulent Augmentation & $+5 \%$ & $\mathrm{~N} / \mathrm{A}$ & $\mathrm{N} / \mathrm{A}$ \\
\hline \multirow{5}{*}{ Uncertainty } & Trajectory & Nominal & $-3 \sigma$ & $+3 \sigma$ \\
& Turbulent Schmidt Number & 0.7 & 0.5 & 1.0 \\
& Trim Angle-of-Attack & Nominal $\alpha_{\text {trim }}$ & $\alpha_{\text {trim }}-5$ & $\alpha_{\text {trim }}+5$ \\
& Surface Emissivity & 0.89 & 0.5 & 1.0 \\
& Transition Location & $X_{\text {tran }}=0$ & $X_{\text {tran }}=0$ & $X_{\text {tran }}=D / 4$ \\
& Distributed Roughness & 0 & $-10 \%$ & $+10 \%$ \\
& Stagnation Augmentation & None & None & $+50 \%$ \\
& Shape Change & None & None & Deformed \\
& Parametric $\left(q_{w}, \tau_{w}, p_{w}\right)$ & 0 & $-(10,10,4) \%$ & $+(10,10,4) \%$ \\
& Other $\left(q_{w}, \tau_{w}, p_{w}\right)$ & 0 & $-(5,5,2) \%$ & $+(5,5,2) \%$
\end{tabular}

applied uniformly along the trajectory. Shape Change refers to the effects of TPS recession and aeroshell deformation on the aerodynamic surface. CFD analysis was performed to determine the environments on a deformed shape with a maximum PICA recession of $0.8 \mathrm{in}$ on the leeside shoulder. Turbulent heat fluxes on the deformed and recessed shape were within $0.5 \%$ of each other, an amount that was considered negligible. The Stagnation Augmentation uncertainty refers to MSL experimental data ${ }^{16}$ in which the stagnation point exhibited a heat flux bump at high Reynolds numbers for unknown reasons. This partial was only applied to those points near the stagnation point. The Parametric uncertainty was included to represent computational modeling inputs e. g. reaction rates, transport properties. Other represents an estimate of uncertainties that are not explicitly addressed.

All CFD cases were run assuming a smooth aerodynamic surface representing the heatshield outer mold line. PICA will char and ablate when exposed to the expected heating in flight, resulting in a roughened surface. If the surface roughness elements extend far enough into the turbulent boundary layer, heat flux and shear stress will be augmented above smooth surface levels. The augmentation of turbulent heat flux and shear stress has been documented many times in experiments. ${ }^{39,40}$ The Distributed Roughness bias in Table 3 captures the expected turbulent heat flux and shear stress augmentation caused by an ablated PICA surface. Roughness effects for MSL were estimated with curve fits of experimental data ${ }^{39}$ that correlate the turbulent shear stress bump factor due to roughness and the roughness Reynolds number $\left(k^{+}\right)$:

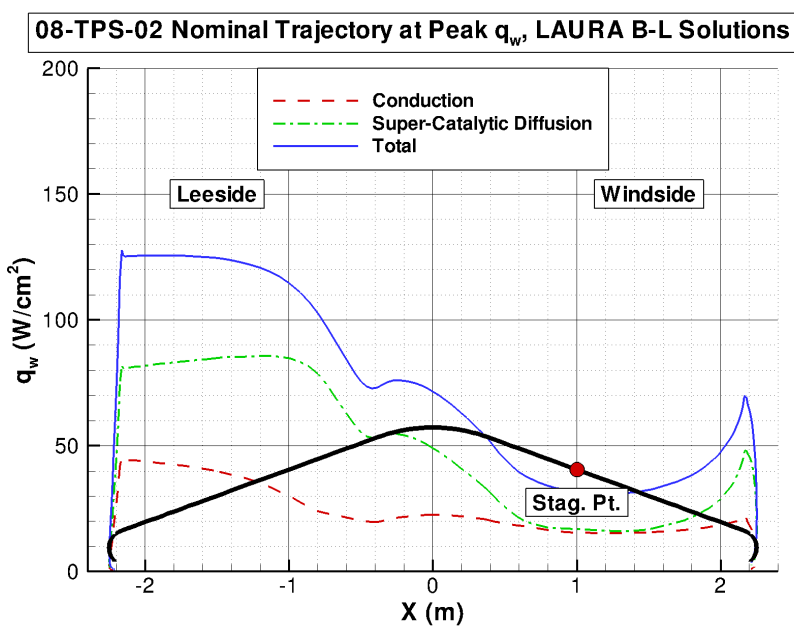

Figure 8. Conduction and Super-Catalytic Diffusion Contributions to 08-TPS-02 Peak Heat Flux

$$
\frac{\tau_{w, k}}{\tau_{w, 0}}=1+0.9\left(\log _{10} k^{+}-1\right), 10<k^{+}<70
$$

where 


$$
k^{+}=\frac{\rho_{w} U_{\tau} k_{s}}{\mu_{w}}
$$

and $k_{s}$ is the equivalent sand grain ${ }^{40}$ roughness height. The heat flux bump factor due to roughness is derived $^{41}$ from Equation 7:

$$
\frac{q_{w, k}}{q_{w, 0}}=1+0.6\left(\frac{\tau_{w, k}}{\tau_{w, 0}}-1\right)
$$

Figure 9a shows the skin friction coefficient (i. e. shear stress) bump factor data used for MSL. The range where $10<k^{+}<70$ is termed the transitionally rough regime. Equation 7 is simply a fit of the middle line in Figure 9a. The 08-TPS-01a roughness Reynolds numbers as computed with the LAURA Baldwin-Lomax model are shown in Figure 9b. Peak leeside shoulder values for $k^{+}$are in the transitionally rough regime and will lead to augmented shear stress and heat flux. The correlations given by Equations 7 and 9 were applied to the LAURA Baldwin-Lomax smooth-wall results as a bias (Table 3). Roughness was also applied as an uncertainty (Table 3) to cover data scatter in Figure 9a.

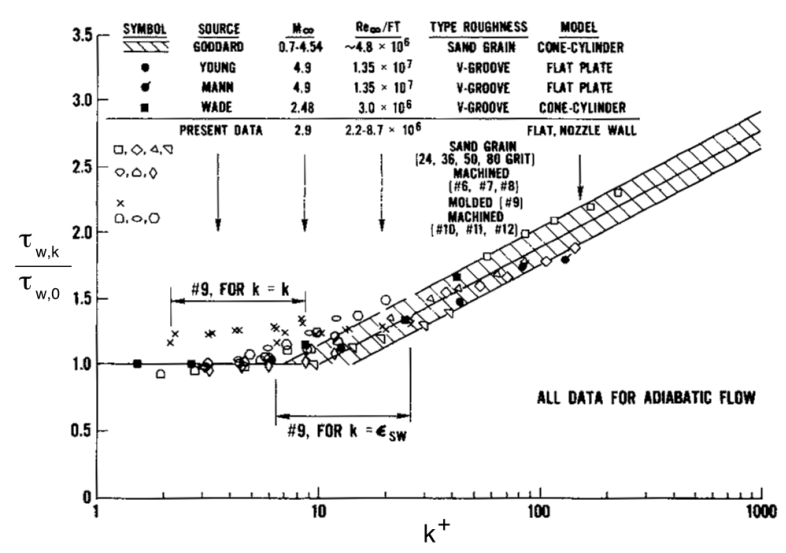

(a) Correlation of Shear Stress Bump Factor vs. Roughness Reynolds Number ${ }^{39}$

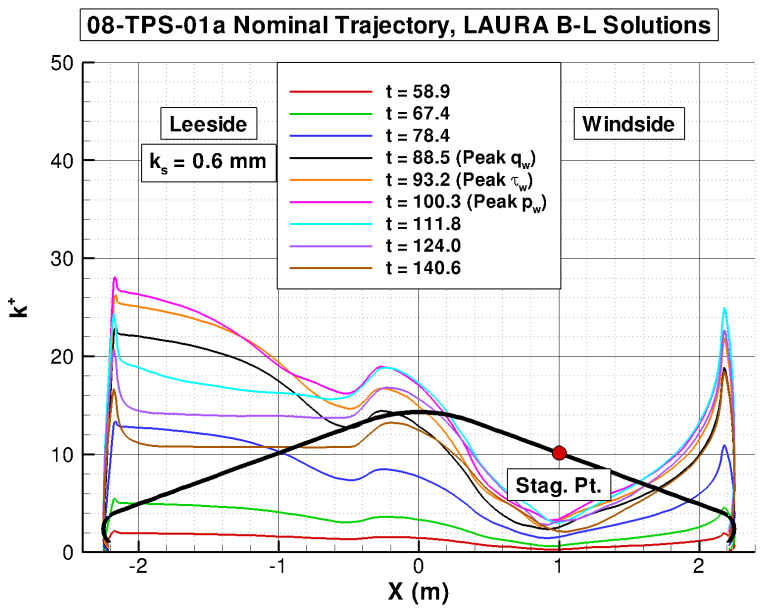

(b) LAURA Roughness Reynolds Number Distributions on the 08-TPS-01a Trajectory $\left(k_{s}=0.6 \mathrm{~mm}\right)$

Figure 9. Distributed Roughness Effects

The assumption for MSL is that the PICA equivalent sand grain roughness is equal to the physical roughness height $\left(k_{s}=k\right.$ in Equation 8). No post-flight measurements of PICA roughness exist where the material has been exposed to turbulent conditions. Stardust post-flight measurements (laminar) showed

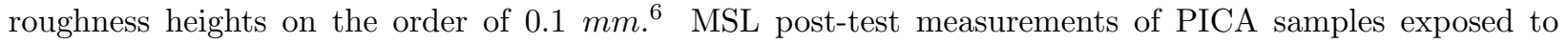
laminar and turbulent conditions showed a maximum roughness height of $0.6 \mathrm{~mm}$; this value was used for the MSL heatshield environments. Figure 10 shows the bump factors along the 08-TPS-01a trajectory using the $0.6 \mathrm{~mm}$ roughness height. The leeside shoulder bump factors are highest (large $k^{+}$), with maximum shear stress and heat flux factors of 1.40 and 1.24, respectively. The bump factors were applied directly to the LAURA smooth wall results prior to adding uncertainties. Given the impact of PICA roughness on the heatshield design environments, MSL convened an independent advisory group to review the analytical methods presented here and to recommend additional testing. ${ }^{6}$ MSL responded to those recommendations that could be accommodated prior to the original 2009 launch date. 
Another mechanism for heat flux augmentation is protruding gap filler material between PICA tiles. TPS testing at some conditions showed that the gap filler material recessed more slowly than the surrounding PICA, causing ridges between tiles. ${ }^{7}$ This mechanism was not specifically included in the design environments since the likelihood of protrusions occurring is $\operatorname{low}^{7}$ in high heating areas and the effects on heating are localized. ${ }^{25}$

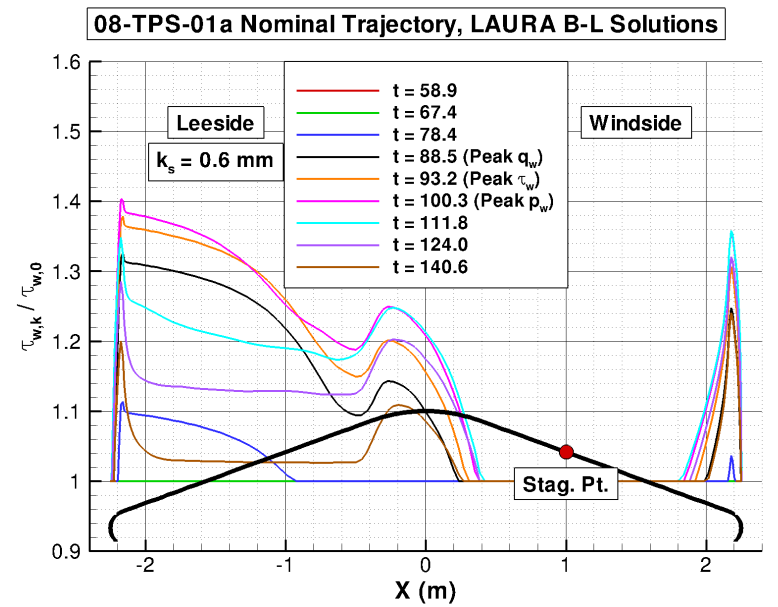

(a) Shear Stress

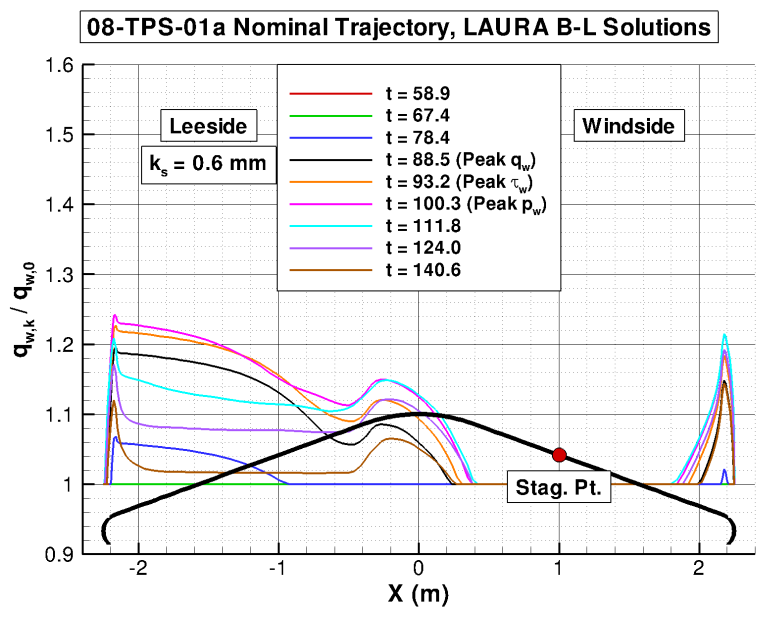

(b) Heat Flux

Figure 10. Bump Factor Distributions due to Distributed Roughness on the 08-TPS-01a Trajectory

Figure 11a shows the 08-TPS-02 baseline (smooth-wall, super-catalytic) peak environments with the individual biases and uncertainties. Maximum baseline heat flux at the leeside shoulder is $128 \mathrm{~W} / \mathrm{cm}^{2}$ prior to application of the biases and uncertainties. The largest leeside shoulder heat flux partial is the Distributed Roughness bias. The same is true for shear stress (not shown). Trim Angle-of-Attack, Trajectory, and Turbulent Schmidt Number are among the largest uncertainty contributors. The total heat flux bias (Equation 5) and uncertainty (Equation 6) are shown in Figure 11b. At the leeside shoulder, the total bias and uncertainty magnitudes are $32 \mathrm{~W} / \mathrm{cm}^{2}$ and $36 \mathrm{~W} / \mathrm{cm}^{2}$, or $25 \%$ and $28 \%$ of the baseline heat flux. At the same location, the cumulative bias plus uncertainty $\left(68 \mathrm{~W} / \mathrm{cm}^{2}\right)$ is about $53 \%$ of the baseline. Note that the heat flux uncertainty associated with the stagnation region augmentation is not represented in Figure 11.

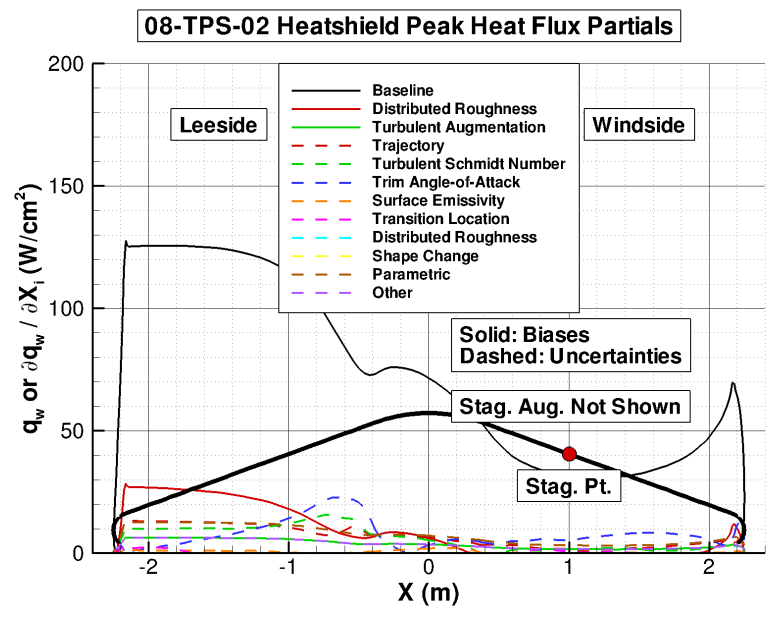

(a) Individual

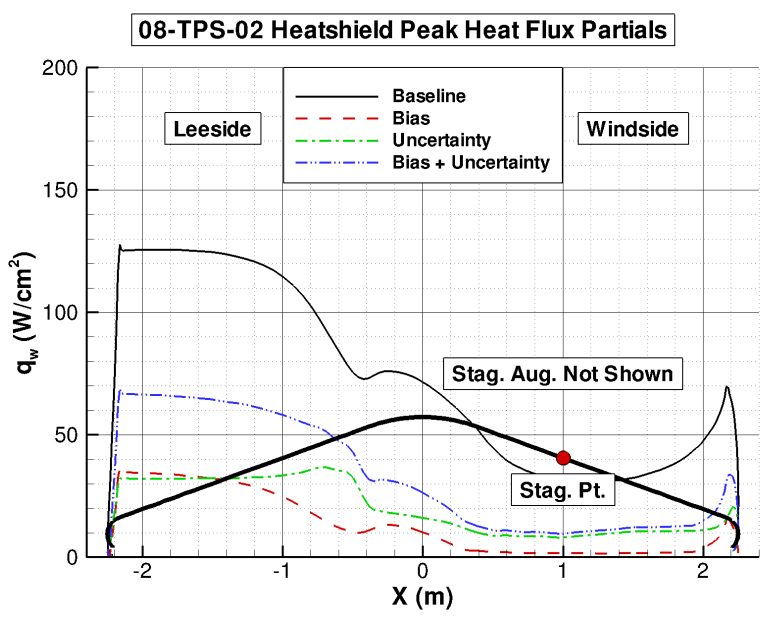

(b) Total

Figure 11. 08-TPS-02 Peak Heat Flux Biases and Uncertainties 


\section{E. Design Environments}

Figure 12 and Table 4 summarize the peak design environments and conditions at the peak locations, regardless of when they are predicted to occur. Peak heat flux, shear stress, and pressure values correspond to the steep 08-TPS-02 trajectory. Design total heat load corresponds to the shallow 08-TPS-01a trajectory. The design values in Table 4 are simply the peak values regardless of trajectory. The Stagnation Augmentation uncertainty for heat flux is not shown in Figure 12a. Turbulent heat flux and shear stress are highest at nearly the same location on the leeside shoulder. At that location, the design values are $197 \mathrm{~W} / \mathrm{cm}^{2}$ for heat flux, $471 \mathrm{~Pa}$ for shear stress, $0.262 \mathrm{~atm}$ for pressure, and $5477 \mathrm{~J} / \mathrm{cm}^{2}$ for total heat load. Maximum design stagnation point pressure is $0.371 \mathrm{~atm}$. The Leeside Flank location requires the most PICA thickness (0.94 in) because the underlying structural density (i. e. thermal mass) is reduced radially outward starting at that location. ${ }^{6}$ The maximum heat flux location has more severe environments, but they are highly localized and are offset by lateral conduction relief in the shoulder. MSL's design heating conditions far exceed what Pathfinder was estimated to have experienced ${ }^{37}\left(118 \mathrm{~W} / \mathrm{cm}^{2}\right.$ and $3800 \mathrm{~J} / \mathrm{cm}^{2}$ assuming laminar super-catalytic conditions). The shear stress and pressure conditions are also unprecedented for a Mars entry capsule.

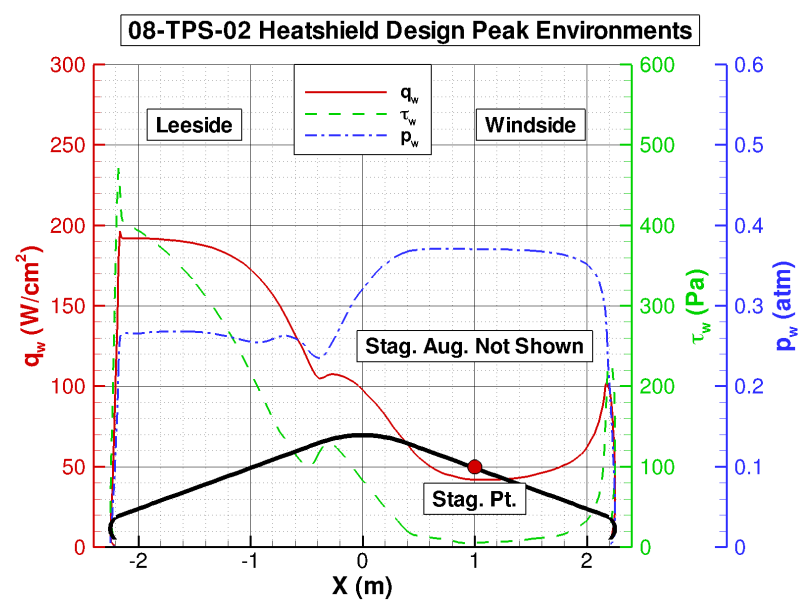

(a) Symmetry Plane Heat Flux, Shear Stress, and Pressure

08-TPS-02 Heatshield Design Peak Shear Stress Environments

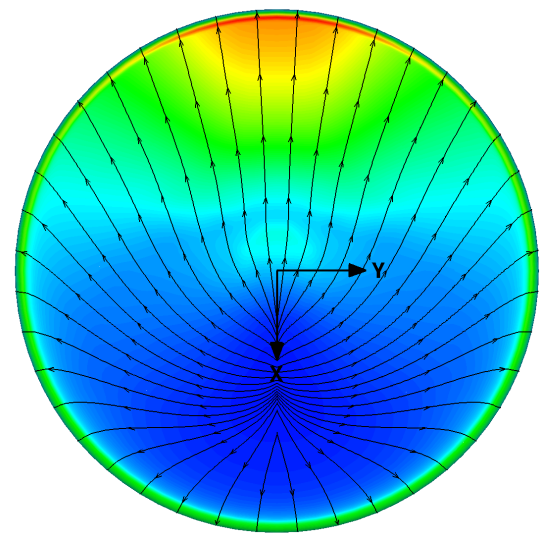

(c) Shear Stress

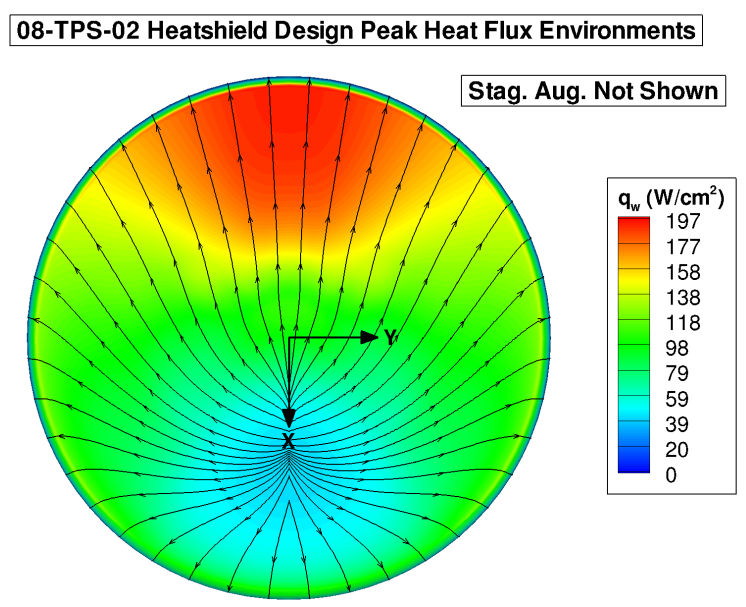

(b) Heat Flux

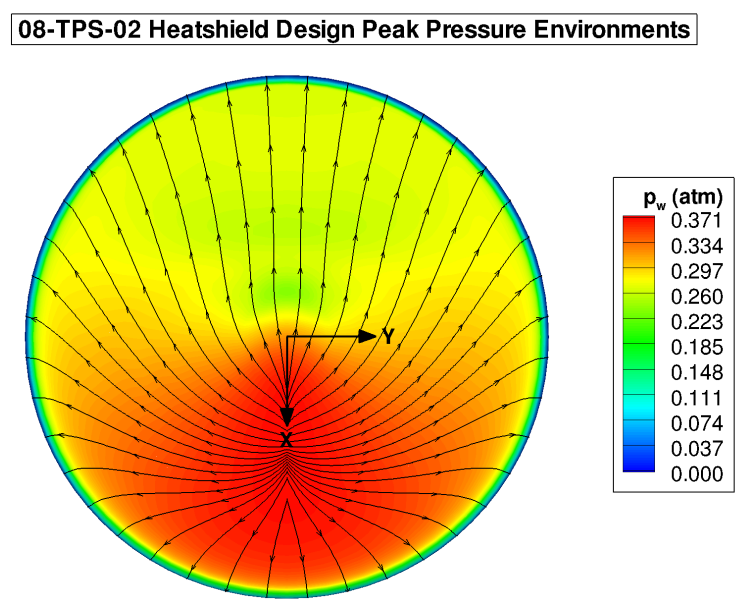

(d) Pressure

Figure 12. Heatshield Design Peak Environments 
Table 4. Heatshield Design Environments

\begin{tabular}{c|c|c|c|c} 
Location & Peak $q_{w}\left(\mathrm{~W} / \mathrm{cm}^{2}\right)$ & Peak $\tau_{w}(\mathrm{~Pa})$ & Peak $p_{w}(\mathrm{~atm})$ & $Q_{w}\left(\mathrm{~J} / \mathrm{cm}^{2}\right)$ \\
\hline \hline Maximum Heat Flux & 197 & 444 & 0.262 & 5477 \\
Maximum Shear Stress & 178 & 471 & 0.227 & 5054 \\
Maximum Pressure & 45 & 10 & 0.371 & 2219 \\
Leeside Flank $(\mathrm{X}=-1.8 \mathrm{~m})$ & 191 & 372 & 0.268 & 5224
\end{tabular}

Figure 13 shows the time-dependent design conditions at the maximum heat flux location on both design trajectories. The heat flux, shear stress, and pressure pulses are offset from one another, so peak values will not occur simultaneously. At all heatshield locations, the heat flux peak occurred first, followed by shear stress and pressure. The leeside shoulder is predicted to experience maximum heat flux and shear stress at essentially the same location and within a few seconds of one another, which will be particularly stressful for the PICA material. Simultaneously high heat flux and shear stress could lead to ablation and mechanical erosion of PICA. Previous entry capsules whose peak heat flux occurred under laminar conditions (e. g. Pathfinder) did not experience significant shear stress at the same location.

Time histories like those shown in Figure 13 were provided for TPS modeling to predict the amount of mass blowing, surface recession, required thickness, etc. during flight. The TPS model includes material response biases and uncertainties analogous to those used for the aerothermodynamic environments. At the limiting location, 0.94 in of PICA are required to maintain a bondline temperature of $250^{\circ} \mathrm{C}^{6}{ }^{6}$ including all thermal analysis biases and uncertainties. The PICA response for MSL is dominated by recession $(0.73$ in maximum) due to the severe conditions and large model uncertainties. ${ }^{6}$ The additional 0.31 in of PICA on the flight heatshield is considered insurance against potential risks in the predicted aerothermodynamics and TPS material response.

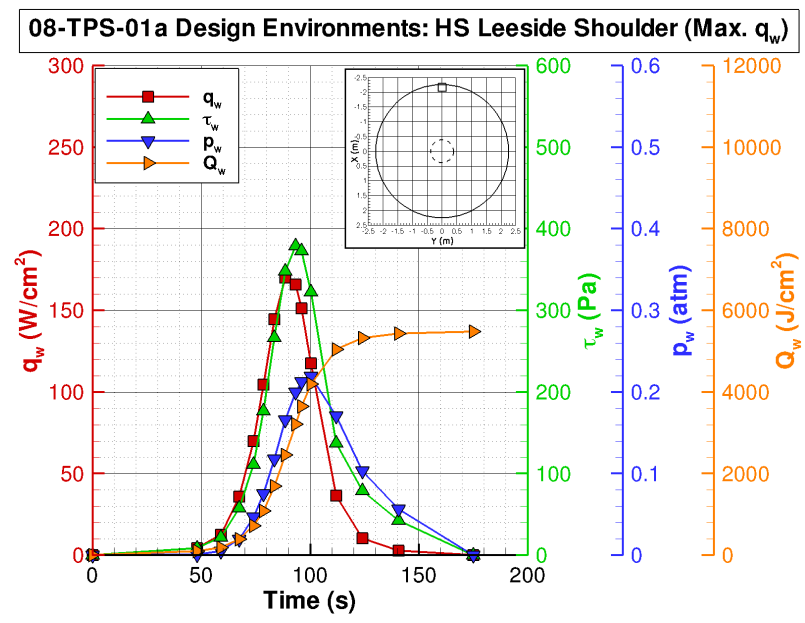

(a) 08-TPS-01a Trajectory

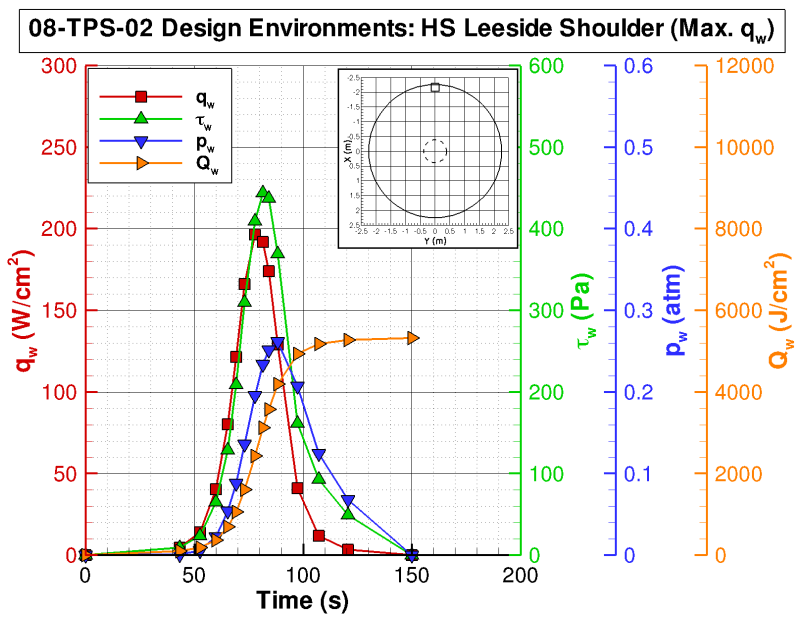

(b) 08-TPS-02 Trajectory

Figure 13. Heatshield Design Environments at the Maximum Heat Flux Location 
Aerothermodynamic environments were also derived for the development of the MSL Entry, Descent, and Landing Instrumentation ${ }^{9}$ (MEDLI) sensors. MEDLI consists of two suites of instrumentation: MEDLI Integrated Sensor Plugs (MISP) temperature/recession sensors and MEDLI Entry Air Data System (MEADS) pressure sensors. The sensor distributions are shown in Figure 14. The sensors are installed into PICA plugs that are subsequently flush-mounted to the flight heatshield. The data collected by MEDLI will be used to reconstruct surface heat flux (MISP) and capsule surface pressure and attitude (MEADS). The MISP locations cover a broad range of expected heat flux environments, including near the maximum heat flux and shear stress on the leeside shoulder (T2/T3). The MEADS locations are concentrated in the higher pressure and lower heat flux/shear stress region near the stagnation point and nose. Biases and uncertainties were developed for each MEDLI sensor location using the method described previously. The design conditions are summarized in Tables 5 and 6.

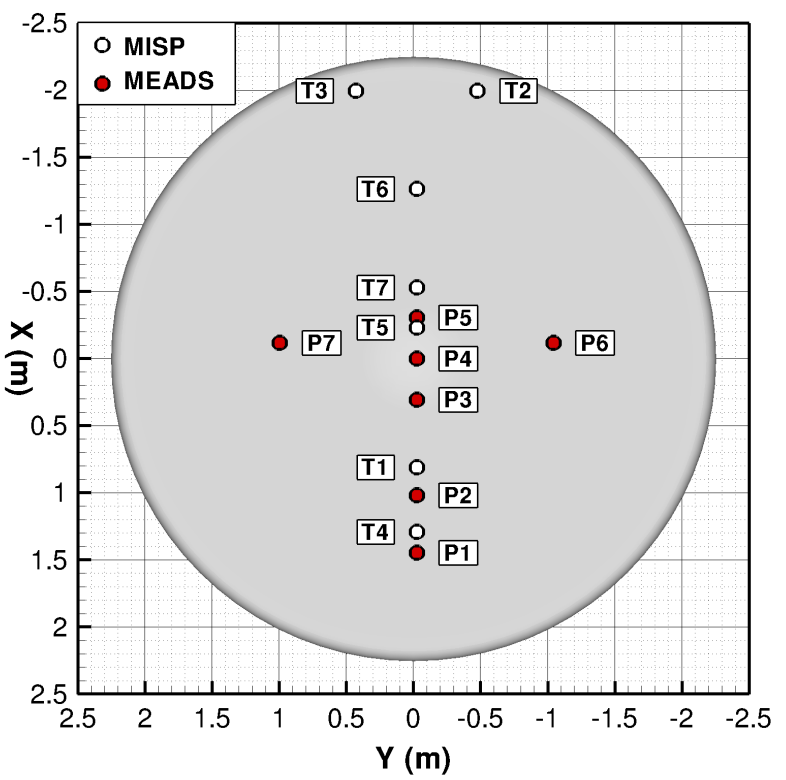

Figure 14. MEDLI Sensor Locations

Table 5. MISP Design Environments

\begin{tabular}{c|c|c|c|c} 
Location & Peak $q_{w}\left(W / \mathrm{cm}^{2}\right)$ & Peak $\tau_{w}(P a)$ & Peak $p_{w}(\mathrm{~atm})$ & $Q_{w}\left(\mathrm{~J} / \mathrm{cm}^{2}\right)$ \\
\hline \hline T1 & 56 & 8 & 0.371 & 2345 \\
T2/T3 & 189 & 376 & 0.267 & 5168 \\
T4 & 52 & 7 & 0.370 & 2092 \\
T5 & 107 & 124 & 0.265 & 3637 \\
T6 & 184 & 285 & 0.264 & 5028 \\
T7 & 118 & 101 & 0.248 & 3711
\end{tabular}

Table 6. MEADS Design Environments

\begin{tabular}{c|c|c|c|c} 
Location & Peak $q_{w}\left(\mathrm{~W} / \mathrm{cm}^{2}\right)$ & Peak $\tau_{w}(\mathrm{~Pa})$ & Peak $p_{w}(\mathrm{~atm})$ & $Q_{w}\left(\mathrm{~J} / \mathrm{cm}^{2}\right)$ \\
\hline \hline P1 & 52 & 8 & 0.369 & 2117 \\
P2 & 53 & 6 & 0.370 & 2169 \\
P3 & 72 & 33 & 0.362 & 2812 \\
P4 & 98 & 83 & 0.322 & 3484 \\
P5 & 107 & 131 & 0.245 & 3591 \\
P6/P7 & 95 & 70 & 0.295 & 3263
\end{tabular}


TPS test facilities cannot simulate the time-dependent conditions that PICA will experience during flight. Rather, the facilities are limited to a small number of simultaneous surface conditions (heat flux, shear stress, and pressure), some of which may not be representative of flight. Given this limitation, the MSL TPS test program focused on testing at conditions at which one, or perhaps two, of the surface conditions were simulated at the same time. ${ }^{7}$ Priority was given to testing in shear conditions to simulate the simultaneously high heat flux and shear stress on the leeside shoulder. Figure 15 shows envelopes of peak conditions that were used to select facilities and test environments. The MSL program used these envelopes to determine test conditions for development and qualification of PICA (Figure 15a) and the MEDLI sensors (Figure 15b and Figure 15c). MISP development required testing near the peak values for both heat flux and shear stress at the same time. MEADS testing focused its testing in high pressure conditions with moderate heat flux and low shear stress.

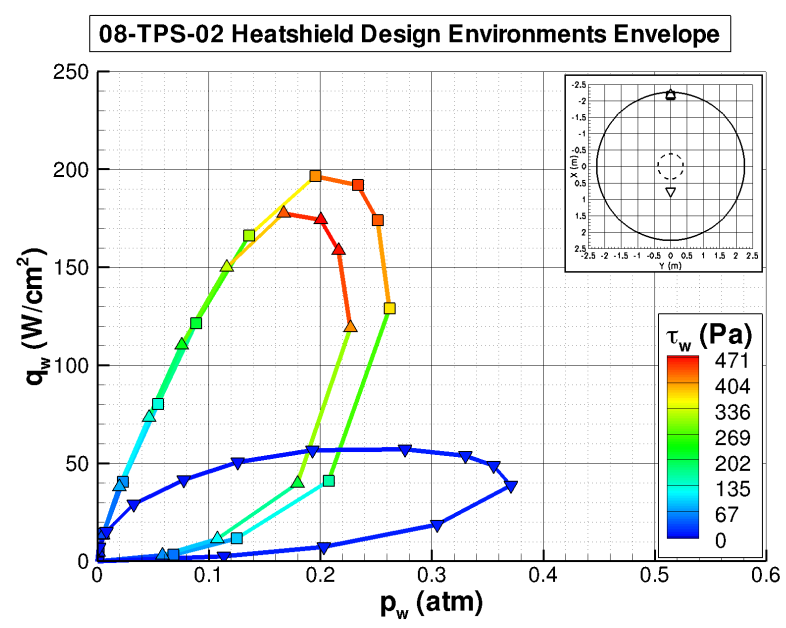

(a) Peak Locations

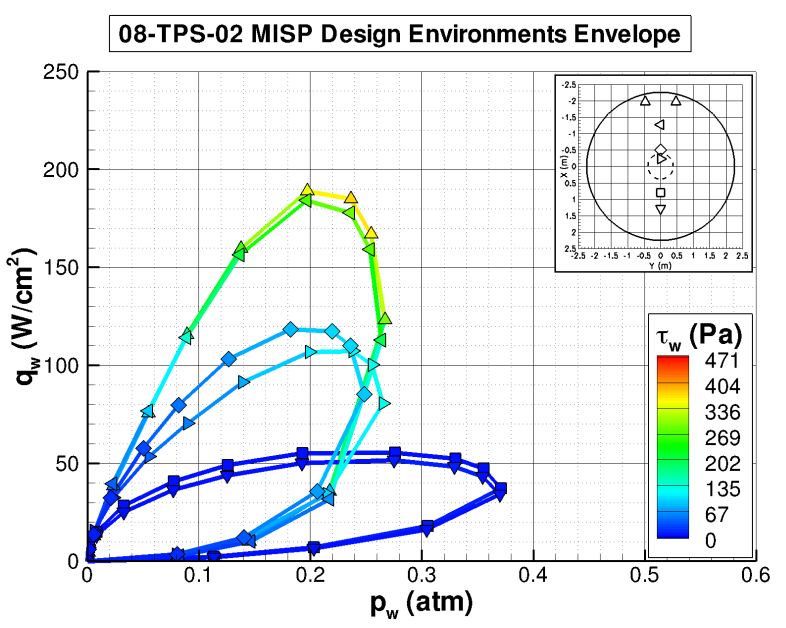

(b) MISP Locations

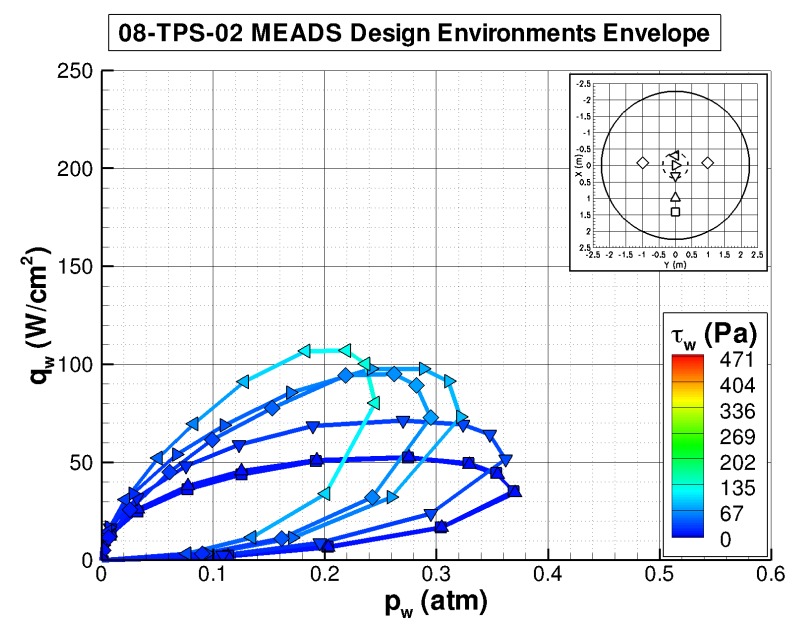

(c) MEADS Locations

Figure 15. Heatshield Design Environments Envelopes 


\section{F. Aerothermodynamic Indicators}

The computation of aerothermodynamic environments via Navier-Stokes flowfield solutions consumes significant time and resources. Any changes to the entry capsule mass properties, atmospheric density profile, launch dates, etc. feed into the design trajectory and require a repeat of the aerothermodynamic design process (Figure 4). In order to avoid having to run CFD for every candidate trajectory, a method was employed in which environments were estimated using curve fits of CFD results from a reference trajectory. This method follows previous work ${ }^{42}$ in which CFD-based surface environments are fit to an equation that depends only on freestream density and velocity:

$$
q_{w}, \tau_{w}, p_{w}=C \rho_{\infty}^{m} V_{\infty}^{n}
$$

where the units are $\mathrm{kg} / \mathrm{m}^{3}$ for $\rho_{\infty}$ and $\mathrm{m} / \mathrm{s}$ for $V_{\infty}$. The coefficient $(C)$ and exponents $(\mathrm{m}, n)$ were derived ${ }^{43}$ to fit Equation 10 to time-varying design conditions, such as those shown in Figure 13.

Figure 16 shows 08-TPS-01a design conditions and derived curve fits (aerothermodynamic indicators) at the maximum heat flux location. The curve fitting parameters are shown in Table 7. The curve fits were anchored to the peak CFD values by adjusting the $C$ coefficients. The benefit of these indicators is that they can be tracked in trajectory simulations to estimate aerothermodynamics on alternative trajectories prior to (or instead of) running CFD solutions. For instance, the effects of landing location or arrival date could be estimated in a fraction of the time it would take to run the CFD solutions by applying the indicators to the new trajectory. Of course, the CFD solutions should be updated for TPS analysis once a final design trajectory is selected.

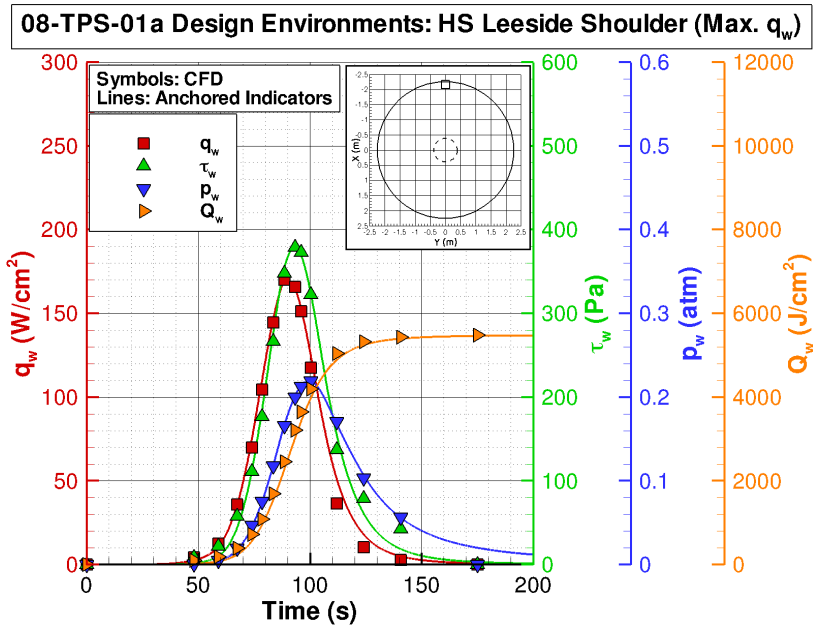

Figure 16. 08-TPS-01a Design Environments and Anchored Indicators at the Maximum Heat Flux Location

Table 7. 08-TPS-01a Indicators at the Maximum Heat Flux Location

\begin{tabular}{r|c|c|c|}
$q_{w}, \tau_{w}, p_{w}=C \rho_{\infty}^{m} V_{\infty}^{n}$ & $C$ & $m$ & $n$ \\
\hline \hline$q_{w}\left(W / \mathrm{cm}^{2}\right)$ & $0.224 \times 10^{-10}$ & 0.879 & 4.22 \\
$\tau_{w}(P a)$ & $0.198 \times 10^{-8}$ & 1.082 & 3.95 \\
$p_{w}(\mathrm{~atm})$ & $0.135 \times 10^{-5}$ & 1.055 & 2.26
\end{tabular}




\section{G. Design Environments for a 2011 Launch}

Aerothermodynamic indicators were used to preview the impact of delaying MSL launch until 2011. Until late 2008, launch was scheduled for late 2009. For various technical and programmatic reasons, the decision was made to delay launch until the next opportunity in late 2011. The major effect of the delayed launch is an increased entry velocity from 5.63 to $5.90 \mathrm{~km} / \mathrm{s}$. The actual magnitude of this velocity increase will vary with arrival date. Before CFD analysis began for the 2011 launch opportunity, aerothermodynamic indicators derived from the 08-TPS-01a/02 trajectories were used to estimate the new environments on an initial 2011 design trajectory. Figure 17 shows indicators derived from 08-TPS-01a at the maximum heat flux location applied to the 09-TPS-01 (shallow entry from a 2011 launch) trajectory. The 09-TPS-01 CFD-based design environments have since been completed using the process described previously. Figure 17 shows that the indicators accurately predicted the CFDbased environments. The peak indicators values are all within $10 \%$ of the CFD peaks.

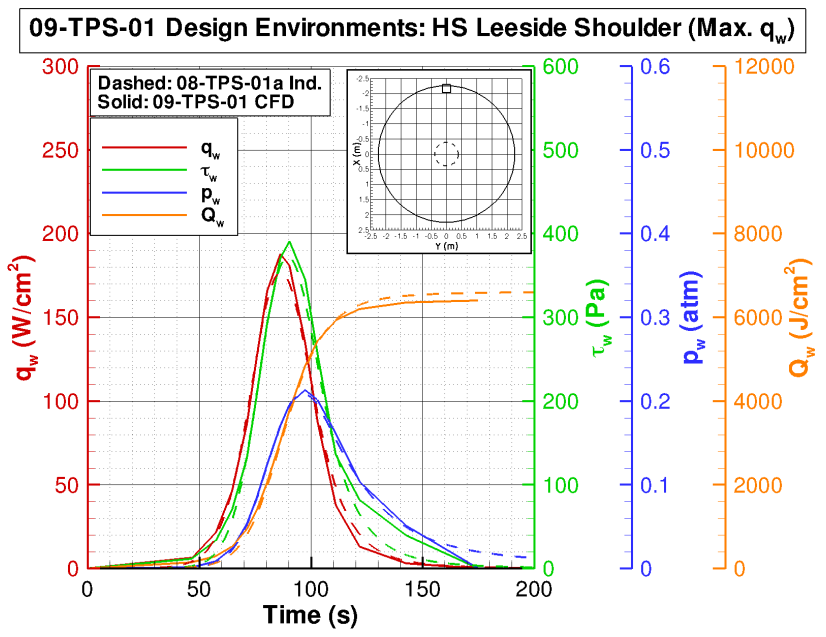

Figure 17. 09-TPS-01 (2011 Launch) Indicator-Based and CFD-Based Design Environments at the Maximum Heat Flux Location

Table 8 compares the design environments at critical locations for the 2009 and 2011 launches. The change in launch date increases turbulent heat flux, shear stress, and total heat load on the leeside shoulder. Conversely, pressure decreases at all locations. An initial TPS assessment ${ }^{6}$ has shown that an additional 0.07 in (1.02 in total) is needed to accommodate the increased heating. As new trajectory analyses are completed for the new launch date, the aerothermal team will revisit the environments analysis to assess the risks introduced and their impacts on the current PICA thickness.

Table 8. Heatshield Design Environments for the 2009 / 2011 Launch Opportunities

\begin{tabular}{c|c|c|c|c} 
Location & Peak $q_{w}\left(\mathrm{~W} / \mathrm{cm}^{2}\right)$ & Peak $\tau_{w}(\mathrm{~Pa})$ & Peak $p_{w}(\mathrm{~atm})$ & $Q_{w}\left(\mathrm{~J} / \mathrm{cm}^{2}\right)$ \\
\hline \hline Maximum Heat Flux & $197 / 226$ & $444 / 466$ & $0.262 / 0.243$ & $5477 / 6402$ \\
Maximum Shear Stress & $178 / 203$ & $471 / 490$ & $0.227 / 0.209$ & $5054 / 5895$ \\
Maximum Pressure & $45 / 48$ & $10 / 5$ & $0.371 / 0.332$ & $2219 / 2042$ \\
Leeside Flank $(\mathrm{X}=-1.8 \mathrm{~m})$ & $191 / 220$ & $372 / 392$ & $0.268 / 0.246$ & $5224 / 5976$
\end{tabular}

\section{Summary and Conclusions}

Aerothermodynamic design conditions (surface heat flux, shear stress, pressure, and total heat load) were derived for the Mars Science Laboratory capsule heatshield for entry following the original 2009 launch. Navier-Stokes flowfield solutions obtained on steep and shallow design trajectories formed the basis of the environments. Chemical and thermal non-equilibrium models were used to simulate the hypersonic and hightemperature conditions that will envelope the entry capsule during Mars atmospheric entry. The expectation of boundary layer transition in flight, a first for Mars entry capsules, necessitated the prediction of fullyturbulent conditions for the design heat pulses. The flowfield solvers using the Baldwin-Lomax algebraic turbulence model agree well with fully-turbulent experimental heating data. Code-to-code discrepancies for flight environments predictions were within normal CFD uncertainties. Biases and uncertainties were added to the baseline CFD results to represent computational uncertainties or phenomena not included in the CFD models. A correction bias was included in the design conditions to account for heatshield TPS surface 
roughness effects on turbulent shear stress and heat flux. At the maximum heat flux location, the heat flux total bias plus uncertainty is more than $50 \%$ of the baseline heating.

The design environments were taken to be the maximum values from either the steep (maximum heat flux, shear stress, and pressure) or shallow (maximum total heat load) design trajectory. The peak design conditions regardless of location are: $197 \mathrm{~W} / \mathrm{cm}^{2}$ heat flux, $471 \mathrm{~Pa}$ shear stress, $0.371 \mathrm{~atm}$ pressure, and $5477 \mathrm{~J} / \mathrm{cm}^{2}$ total heat load. Location-specific conditions were derived as a function of time and used in modeling and testing of the heatshield TPS material. A method of estimating aerothermodynamic conditions on alternative trajectories was developed using curve fits of existing CFD-based environments. Finally, delaying MSL launch until 2011 will increase design peak heat flux and total heat load mostly due to a higher atmospheric entry velocity.

\section{Acknowledgments}

The authors wish to thank the members of the MSL Aeroheating Working Group from NASA Langley and Ames Research Centers, NASA Jet Propulsion Laboratory, and Lockheed Martin Astronautics for their valuable contributions to the MSL aerothermodynamics analysis and thermal protection system design. Thanks also to Victor Lessard at NASA Langley Research Center for generating computational grids used for the LAURA flowfield calculations.

\section{References}

\footnotetext{
${ }^{1}$ Steltzner, A., et al, "Mars Science Laboratory Entry, Descent and Landing System," IEEE Paper 2006-1307, IEEE Aerospace Conference, Big Sky, Montana, March 2006.

${ }^{2}$ Anonymous, "Entry Data Analysis for Viking Landers 1 and 2 Final Report," TN-3770218 (also NASA CR-159388), Martin Marietta Corp., November, 1976.

${ }^{3}$ Braun, R. D., Powell, R. W., Engelund, W. C., Gnoffo, P. A., Weilmuenster, K. J., and Mitcheltree, R. A., "Mars Pathfinder Six-Degree-of-Freedom Entry Analysis," Journal of Spacecraft and Rockets, Vol. 32, No. 6, November-December, 1995, pp. 670-676.

${ }^{4}$ Desai, P., Schoenenberger, M., and Cheatwood, F. M., "Mars Exploration Rover Six-Degree-of-Freedom Entry Trajectory Analysis," Journal of Spacecraft and Rockets, Vol. 43, No. 5, September-October, 2006, pp. 1019-1025.

${ }^{5}$ Desai, P. N., Prince, J. L., Queen, E. M., Cruz, J. R., and Grover, M. R., "Entry, Descent, and Landing Performance of the Mars Phoenix Lander," AIAA Paper 2008-7346, AIAA Atmospheric Flight Mechanics Conference, Honolulu, Hawaii, August, 2008.

${ }^{6}$ Wright, M., Beck, R., Edquist, K., Driver, D., Sepka, S., and Slimko, E., "Sizing and Margins Assessment of the Mars Science Laboratory Aeroshell Thermal Protection System," AIAA Paper 2009-4231, AIAA Thermophysics Conference, San Antonio, Texas, June 2009.

${ }^{7}$ Beck, R. A. S., et al, "Development of the Mars Science Laboratory Heatshield Thermal Protection System," AIAA Paper 2009-4229, AIAA Thermophysics Conference, San Antonio, Texas, June 2009.

${ }^{8}$ Driver, D. et al. "Arc Jet Testing in a Shear Environment for Mars Science Laboratory Thermal Protection System," AIAA Paper No. 2009-4230, AIAA Thermophysics Conference, San Antonio, Texas, June 2009.

${ }^{9}$ Gazaric, M., Wright, M., Little, A., Cheatwood, F. M., Herath, J., Munk, M., Novak, F., and Martinez, E., Overview of the MEDLI Project, IEEE Paper 2008-1510, IEEE Aerospace Conference, Big Sky, Montana, March 2008.

${ }^{10}$ Edquist, K. T., Dyakonov, A. A., Wright, M. J., and Tang, C.-Y., "Aerothermodynamic Design of the Mars Science Laboratory Backshell and Parachute Cone," AIAA Paper 2009-4075, AIAA Thermophysics Conference, San Antonio, Texas, June 2009.

${ }^{11}$ Edquist, K. T., Hollis, B. R., Dyakonov, A. A., Laub, B., Wright, M. J., Rivellini, T. P., Slimko, E. M., and Willcockson, W. H., "Mars Science Laboratory Entry Capsule Aerothermodynamics and Thermal Protection System," IEEEAC Paper 1423, IEEE Aerospace Conference, Big Sky, Montana, March 2007.

${ }^{12}$ Edquist, K. T., Dyakonov, A. A., Wright, M. J., and Tang, C.-Y., "Aerothermodynamic Environments Definition for the Mars Science Laboratory Entry Capsule," AIAA Paper 2007-1206, AIAA Aerospace Sciences Meeting and Exhibit, Reno, Nevada, January 2007.

${ }^{13}$ Edquist, K. T., Liechty, D. S., Hollis, B. R., Alter, S. J., and Loomis, M. P., "Aeroheating Environments for a Mars Smart Lander," Journal of Spacecraft and Rockets, Vol. 43, No. 2, March-April, 2006, pp. 330-339.

${ }^{14}$ Edquist, K. T., "Afterbody Heating Predictions for a Mars Science Laboratory Entry Vehicle," AIAA Paper 2005-4817, AIAA Thermophysics Conference, Toronto, Ontario, Canada, June 2005.

${ }^{15}$ Edquist, K. T., and Alter, S. J., "Computational Aeroheating Predictions for Mars Lander Configurations," AIAA Paper 2003-3639, AIAA Thermophysics Conference, Orlando, Florida, June 2003.

${ }^{16}$ Hollis, B. R. and Collier, A. S., "Turbulent Aeroheating Testing of Mars Science Laboratory Entry Vehicle in Perfect-Gas Nitrogen," AIAA Paper 2007-1208, AIAA Aerospace Sciences Meeting and Exhibit, Reno, Nevada, January 2007.

${ }^{17}$ Liechty, D. S. and Hollis, B. R., "Mars Science Laboratory Experimental Aerothermodynamics with Effects of Cavities and Control Surfaces," Journal of Spacecraft and Rockets, Vol. 43, No. 2, March-April 2006, pp. 340-353.
} 
${ }^{18}$ Hollis, B. R., Liechty, D. S., Wright, M. J., Holden, M. S., Wadhams, T. P., MacLean, M., and Dyakonov, A., "Transition Onset and Turbulent Heating Measurements for the Mars Science Laboratory Entry Vehicle," AIAA Paper 2005-1437, AIAA Aerospace Sciences Meeting and Exhibit, Reno, Nevada, January 2005.

${ }^{19}$ Liechty, D. S. and Hollis, B. R., "Heat Shield Cavity Parametric Experimental Aeroheating for a Proposed Mars Smart Lander Aeroshell," AIAA Paper 2002-2746, AIAA Fluid Dynamics Conference and Exhibit, St. Louis, Missouri, June 2002.

${ }^{20}$ Hollis, B. R. and Liechty, D. S., "Boundary Layer Transition Correlations and Aeroheating Predictions for Mars Smart Lander," AIAA Paper 2002-2745, AIAA Fluid Dynamics Conference and Exhibit, St. Louis, Missouri, June 2002.

${ }^{21}$ Wright, M. J., Olejniczak, J., Brown, J. L., Hornung, H. G., and Edquist, K. T., Computational Modeling of T5 Laminar and Turbulent Heating Data on Blunt Cones, Part 2: Mars Applications," AIAA Paper 2005-0177, AIAA Aerospace Sciences Meeting and Exhibit, Reno, Nevada, January 2005.

${ }^{22}$ Willcockson, W. H., "Mars Pathfinder Heatshield Design and Flight Experience," Journal of Spacecraft and Rockets, Vol. 36, No. 3, May-June 1999.

${ }^{23}$ Tran, H., Johnson, C. E., Rasky, D. J., Hui, F. C., Hsu, M.-T., Chen, T., Chen, Y.-K., Paragas, D., and Kobayashi, L., "Phenolic Impregnated Carbon Ablators (PICA) as Thermal Protection Systems for Discovery Missions," NASA TM-110440, April 1997.

${ }^{24}$ Olynick, D., Chen, Y.-K, and Tauber, M. E., "Forebody TPS Sizing with Radiation and Ablation for the Stardust Sample Return Capsule," AIAA-972474, AIAA Thermophysics Conference, Atlanta, Georgia, June, 1997.

${ }^{25}$ Tang, C., Edquist, K. T., Wright, M. J., Sepka, S., and Cassel, A., "Numerical Simulations of Protruding Gapfillers on the Mars Science Laboratory Heatshield," AIAA Paper 2009-4077, AIAA Thermophysics Conference, San Antonio, Texas, June 2009 .

${ }^{26}$ Wright, M. J., Edquist, K. T., Hollis, B. R., Olejniczak, J., and Venkatapathy, E., "Status of Aerothermal Modeling for Current and Future Mars Exploration Missions," IEEEAC Paper 1428, IEEE Aerospace Conference, Big Sky, Montana, March 2006.

${ }^{27}$ Cheatwood, F. M. and Gnoffo, P. A., "Users Manual for the Langley Aerothermodynamic Upwind Algorithm (LAURA)," NASA TM-4674, April 1996.

${ }^{28}$ Wright, M. J., Candler, G. V., and Bose, D., "Data-Parallel Line Relaxation Method for the Navier-Stokes Equations," AIAA Journal, Vol. 36, No. 9, 1998, pp. 1603-1609.

${ }^{29}$ Gnoffo, P. A., Braun, R. D., Weilmuenster, K. J., Mitcheltree, R. A., Engelund, W. C., and Powell, R. W., "Prediction and Validation of Mars Pathfinder Hypersonic Aerodynamic Data Base," Journal of Spacecraft and Rockets, Vol. 36, No. 3, May-June 1999.

${ }^{30} \mathrm{McDaniel}$, R. D., Wright, M. J., and Songer, J. T., "Aeroheating Predictions for Phoenix Entry Vehicle," AIAA Paper 2008-1279, AIAA Aerospace Sciences Meeting and Exhibit, Reno, Nevada, January 2008.

${ }^{31}$ Cheatwood, F. M., Merski, Jr., N. R., Riley, C. J., and Mitcheltree, R. M., "Aerothermodynamic Environment Definition for the Genesis Sample Return Capsule," AIAA 2001-2889, AIAA Thermophysics Conference, Anaheim, California, June 2001.

${ }^{32}$ Tang, C. and Wright, M. J., "Analysis of the Forebody Aeroheating Environment During Genesis Sample Return Capsule Reentry," AIAA Paper 2007-1207, AIAA Aerospace Sciences Meeting and Exhibit, Reno, Nevada, January 2007.

${ }^{33}$ Schoenenberger, M., Dyakonov, A., Buning, Scallion, W., and Van Norman, J., "Aerodynamic Challenges for the Mars Science Laboratory Entry Descent and Landing," AIAA Paper 2009-3914, AIAA Thermophysics Conference, San Antonio, Texas, June 2009 .

${ }^{34}$ Dyakonov, A., Schoenenberger, M., Scallion, W., Van Norman, J., Novak, L., and Tang, C., "Aerodynamic Interference Due to MSL Reaction Control System," AIAA Paper 2009-3915, AIAA Thermophysics Conference, San Antonio, Texas, June 2009.

${ }^{35}$ Baldwin, B. and Lomax, H., "Thin Layer Approximation and Algebraic Model for Separated Turbulent Flows," AIAA Paper 1978-257, AIAA Aerospace Sciences Meeting, Huntsville, Alabama, January 1978.

${ }^{36}$ Menter, F. R., "Two Equation Eddy-Viscosity Turbulence Models for Engineering Applications," AIAA Journal, Vol. 32, No. 8, 1994, pp. 1598-1605.

${ }^{37}$ Milos, F. S., Chen, Y.-K., Congdon, W. M., and Thornton, J. M., "Mars Pathfinder Entry Temperature Data, Aerothermal Heating, and Heatshield Material Response," Journal of Spacecraft and Rockets, Vol. 36, No. 3, May-June 1999

${ }^{38}$ Bose, D., Wright, M. J., and Palmer, G. E., "Uncertainty Analysis of Laminar Aeroheating Predictions for Mars Entries," Journal of Thermophysics and Heat Transfer, Vol. 20, No. 4, October-December 2006, pp. 652-662.

${ }^{39}$ Reda, D. C., Ketter, F. C., and Fan, F., "Compressible Turbulent Skin Friction on Rough and Rough/Wavy Walls in Adiabatic Flow," AIAA Paper 74-574, AlAA Fluid and Plasma Dynamics Conference, Palo Alto, California, June 1974.

${ }^{40}$ Dirling, Jr., R. B., A Method for Computing Roughwall Heat Transfer Rates on Reentry Nosetips," AIAA Paper 73-763, AIAA Thermophysics Conference, Palm Springs, California, July 1973. 1976.

${ }^{41}$ Dahm, T. J., et. el., "Passive Nosetip Technology (PANT II) Program," SAMSO-TR-77-11, Accurex Corporation, October

${ }^{42}$ Olynick, D., Loomis, M., Chen, Y.-K., Venkatapathy, E., and Allen, G., "New TPS Design Strategies for Planetary Entry Vehicle Design," AIAA Paper AIAA 99-0348, AIAA Aerospace Sciences Meeting and Exhibit, Reno, Nevada, January 1999.

${ }^{43}$ Nielsen, H. B., "UCMINF - An Algorithm for Unconstrained, Nonlinear Optimization," Technical Report IMM-REP2000-19, Technical University of Denmark, DK-2800 Lyngby, Denmark, December 2000. 